ISSN: 0131-6230, eISSN: 2312-6965, https://doi.org/10.21455/si,

http://elibrary.ru/title_about.asp? id $=25597$

English translation: Seismic Instruments, ISSN: $0747-9239$ (Print) 1934-7871 (Online), https://link.springer.com/journal/11990

Сейсмические приборы. 2019. T. 55, № 1. C.5-28. https://doi.org/10.21455/si2019.1-1

The metadata in English is presented at the end of the article!

УДК 550.34: 556.33

PACS: 91.30.Px

\title{
Статистический анализ прецизионных данных наблюдений за уровнем подземных вод в сейсмоактивном регионе (на примере скважины Ю3-5, Камчатка)
}

\author{
(C) 2019 г. Г.Н. Копылова ${ }^{1}$, А.А. Любушин ${ }^{2}$, С.В. Болдина ${ }^{1}$ \\ ${ }^{1}$ Камчатский филиал Федерального исследовательского иентра “Единая геофизическая служба \\ Российской академии наук”, г. Петропавловск-Камчатский, Россия \\ ${ }^{2}$ Институт физики Земли им. О.Ю. Шмидта РАН, г. Москва, Россия \\ Автор для переписки: Г.Н. Копылова, e-mal: gala@emsd.ru
}

\begin{abstract}
Аннотация
Представлен новый метод статистического анализа уровнемерных данных, нацеленный на выделение кратковременных возмущенных состояний наблюдательной скважины, на примере данных наблюдений в скважине Ю3-5, Восточная Камчатка. Используемые данные примечательны своей детальностью - интервал измерений уровня и атмосферного давления составлял 5 мин, чувствительность регистрации уровня воды \pm 0.1 см, атмосферного давления - \pm 0.1 гПа, а также тем, что в течение наблюдений в 2012-2018 гг. произошли пять сильных землетрясений с $M_{w}=6.5-8.3$ на эпицентральных расстояниях $d_{e}=80-700$ км. Применение факторного и кластерного анализа к последовательности многомерных векторов восьми статистических свойств ряда наблюдений за уровнем воды в последовательных временных окнах длиной 1 сут, после адаптивной компенсации влияния атмосферного давления, позволило выделить четыре различных статистически значимых состояния временного ряда, между которыми происходят переключения во времени. Три из выделенных состояний временного ряда, проявляющиеся с суммарной вероятностью 0.987 , рассматриваются в качестве фоновых. Геофизическая интерпретация проявлений “аномального” состояния временного ряда уровня воды, возникающего с вероятностью 0.013 , проводится в сопоставлении с сильными землетрясениями, техническими условиями наблюдений и другими факторами. Показано, что применение представленного метода обработки экспериментальных данных позволяет выделять скрытые в шуме кратковременные аномалии гидрогеодинамического режима скважины, что является существенным дополнением к традиционной обработке уровнемерных данных, нацеленной в основном на выделение низкочастотного тренда в изменениях уровня воды. Представленный метод может найти применение в задачах геофизического мониторинга сейсмоактивных территорий и поиска предвестников землетрясений при оперативной обработке данных уровнемерных наблюдений в скважинах.
\end{abstract}

Ключевые слова: скважина, уровень воды, землетрясение, Камчатка, временной ряд, адаптивная фильтрация, факторный анализ, кластерный анализ

Цитируйте эту статью как: Копылова Г.Н., Любушин А.А., Болдина С.В. Статистический анализ прецизионных данных наблюдений за уровнем подземных вод в сейсмоактивном регионе (на примере скважины Ю3-5, Камчатка) // Сейсмические приборы. 2019. Т. 55, № 1. C.5-28. https://doi.org/10.21455/si2019.1-1 


\section{Введение}

Прецизионные измерения уровня воды в скважинах позволяют диагностировать изменения давления подземных вод в диапазоне периодов от секунд-минут до десятков-сотен суток. В качестве механизмов, влияющих на вариации давления, могут выступать квазиупругая деформация водовмещающих пород, развитие в них трещинной дилатансии и других процессов изменения их емкости и проницаемости [Киссин, 1993, 2009; Копылова, 2006б]. Чувствительность давления подземных вод к изменениям напряженно-деформированного состояния горных пород определяет использование уровнемерных данных в решении широкого круга задач в науках о Земле. По данным о вариациях уровня воды в скважинах исследуются лунно-солнечные приливные процессы в твердой земле [Bredehoeft, 1967; Rojstaczer, Agnew, 1989; Любушин и др., 1997; Виноградов и др., 2011]. В работах [Любушин, Малугин, 1993; Любушин, Лежнев, 1995; Копьлова и др., 2000] показана возможность оценки изменчивости свойств земной коры по отклику уровня воды на вариации атмосферного давления.

В сейсмоактивных регионах уровнемерные наблюдения используются для изучения эффектов сейсмичности в изменениях уровня воды-воздействия сейсмических волн, косейсмической деформации водовмещающих пород и гидрогеодинамических предвестников землетрясений [Roeloffs, 1988; Roeloffs et al., 1989; Igarashi, Wakita, 1991; Киссин, 1993, 2009; Копылова, 2006б; Копьлова и др., 2010; Wang, Manga, 2010]. Работами последних лет на Камчатке показано, что применение традиционных методов обработки данных уровнемерных наблюдений [Копылова, 2001, 2006а], нацеленных на выделение низкочастотного тренда в изменениях уровня воды, позволяет выделять гидрогеодинамические предвестники (далее - ГП) перед сильными местными землетрясениями. ГП проявлялись в изменениях уровня воды в течение времени от первых десятков суток до месяцев-лет перед землетрясениями с величинами магнитуд порядка 7-8 на эпицентральных расстояниях до первых сотен км от наблюдательных скважин [Копылова и др., 2000; Копьлова, 2001, 2006а; Болдина, Копьлова, 2017]. В [Чебров и др., 2011; Фирстов $u$ др., 2016] приводятся примеры успешных среднесрочных прогнозов сильных камчатских землетрясений с использования ГП.

Вместе с тем, вопрос о выделении относительно кратковременных аномальных состояний гидрогеодинамического режима скважин, скрытых в шумовых вариациях уровня воды, открыт и требует своего решения применительно к задачам поиска краткосрочных ГП и других сигналов геодинамической активности. Необходимость диагностики предвестников землетрясений во временных рядах уровнемерных наблюдений в широком диапазоне периодов предполагает развитие методов обработки экспериментальных данных с использованием формализованных процедур статистического анализа для последующего создания унифицированного программного обеспечения этого вида геофизических наблюдений.

В настоящей работе на примере скважины Ю3-5 (Камчатка) рассматривается новый способ статистического анализа временного ряда 5-минутных уровнемерных данных, после адаптивной компенсации в нем барометрических вариаций, с применением факторного и кластерного анализа к последовательности многомерных векторов восьми статистических свойств ряда наблюдений в последовательных временных окнах длиной 1 сут. В поведении ряда выделены четыре различных статистически значимых состояния, между которым происходят переключения во времени. При этом три из выделенных четырех состояний рассматриваются в качестве фоновых и одно - в качестве “аномального". Геофизическая интерпретация проявлений “аномального" состояния временного ряда проводится в сопоставлении с произошедшими сильными землетрясениями, техническими условиями наблюдений и другими факторами. 


\section{Технические условия наблюдений и исходные данные}

Камчатский филиал Федерального исследовательского центра "Единая геофизическая служба Российской академии наук” (КФ ФИЦ ЕГС РАН) с 2003 г. проводит наблюдения за вариациями уровня воды в скважине Ю3-5 с интервалом измерений 5 мин с использованием аппаратурного комплекса, созданного в ООО Полином, г. Хабаровск [Копьлова и др., 2016].

Координаты скважины Ю3-5 53.169 с.ш., 158.414ㅇ‥, глубина 800 м. В диапазоне глубин 0-310 м ствол скважины обсажен металлической трубой. На глубинах 310 800 м ствол скважины открыт и связан с водовмещающими породами, представленными чередованием слоев алевролитов и сланцев позднемелового возраста. Водопроводимость пород $7.8 \mathrm{~m}^{2} /$ сут, минерализация подземной воды 0.25 г/л. Уровень воды находится на глубине 1-1.5 м ниже поверхности земли.

В изменениях уровня воды были выделены внутригодовая сезонность с амплитудой до 50 см [Болдина, Копылова, 2017], а также барометрические и приливные вариации [Копылова, 2006а]. При местных сильных землетрясениях проявляются ко- и постсейсмические вариации в изменениях уровня воды. Перед Кроноцким (5 декабря 1997 г., $\left.M_{w}=7.8\right)$ и Жупановским (30 января 2016 г., $\left.M_{w}=7.2\right)$ землетрясениями в изменениях уровня воды были ретроспективно выделены гидрогеодинамические предвестники [Копьлова, 2006а; Копьлова, Болдина, 2012; Болдина, Копылова, 2017]. При прохождении поверхностных сейсмических волн от сильнейших землетрясений с $M_{w}$ порядка 8-9 на эпицентральных расстояниях сотни-тысячи километров проявлялись колебания уровня воды с амплитудами до 9 см продолжительностью от нескольких часов до одних суток (гидросейсмы). Более детальные данные о строении скважины, упругих и фильтрационных свойствах водовмещающих пород, закономерностях гидрогеодинамического режима и эффектах землетрясений в изменениях уровня воды представлены в предыдущих публикациях [Копылова, 2006а; Копьлова, Болдина, 2006; Копьлова и др., 2010, 2016; Болдина, Копьлова, 2016, 2017] и других работах.

Используемая аппаратура характеризуется высоким разрешением (чувствительность регистрации уровня воды $\pm 0.1 \mathrm{~cm}$, атмосферного давления - \pm 0.1 гПа), достаточным динамическим диапазоном, долговременной стабильностью и надежностью при проведении непрерывных наблюдений. Для сохранности оборудования над оголовком скважины установлено железобетонное защитное сооружение с металлической дверью. Технический контроль функционирования системы наблюдений выполняется сотрудниками лаборатории геофизических исследований и включает регулярные, не реже одного раза в квартал, посещения скважины для тестирования и профилактики оборудования. Даты и время посещений скважины, перечень выполняемых работ и результаты тестирования фиксируются в электронном журнале. Обработка и оперативный анализ текущих данных, поступающих в КФ ФИЦ ЕГС РАН по каналам сотовой связи, осуществляются оператором ежедневно, что дает дополнительные возможности контроля технического состояния системы наблюдений.

В работе использовались временные ряды измерений уровня воды и атмосферного давления с 27.07.2012 г. по 01.02.2018 г. с дискретизацией 5 мин, всего 2015 сут (рис. 1). Полная длина записей уровня и атмосферного давления составляет 580605 5-минутных отсчетов. В записях имеются 424 единичных пропуска данных по причине технических сбоев системы регистрации, что составляет $0.007 \%$ от общей длины временных рядов уровня и атмосферного давления. Учет пропущенных значений во временных рядах проводился линейной интерполяцией между ближайшими зарегистрированными отсчетами. 


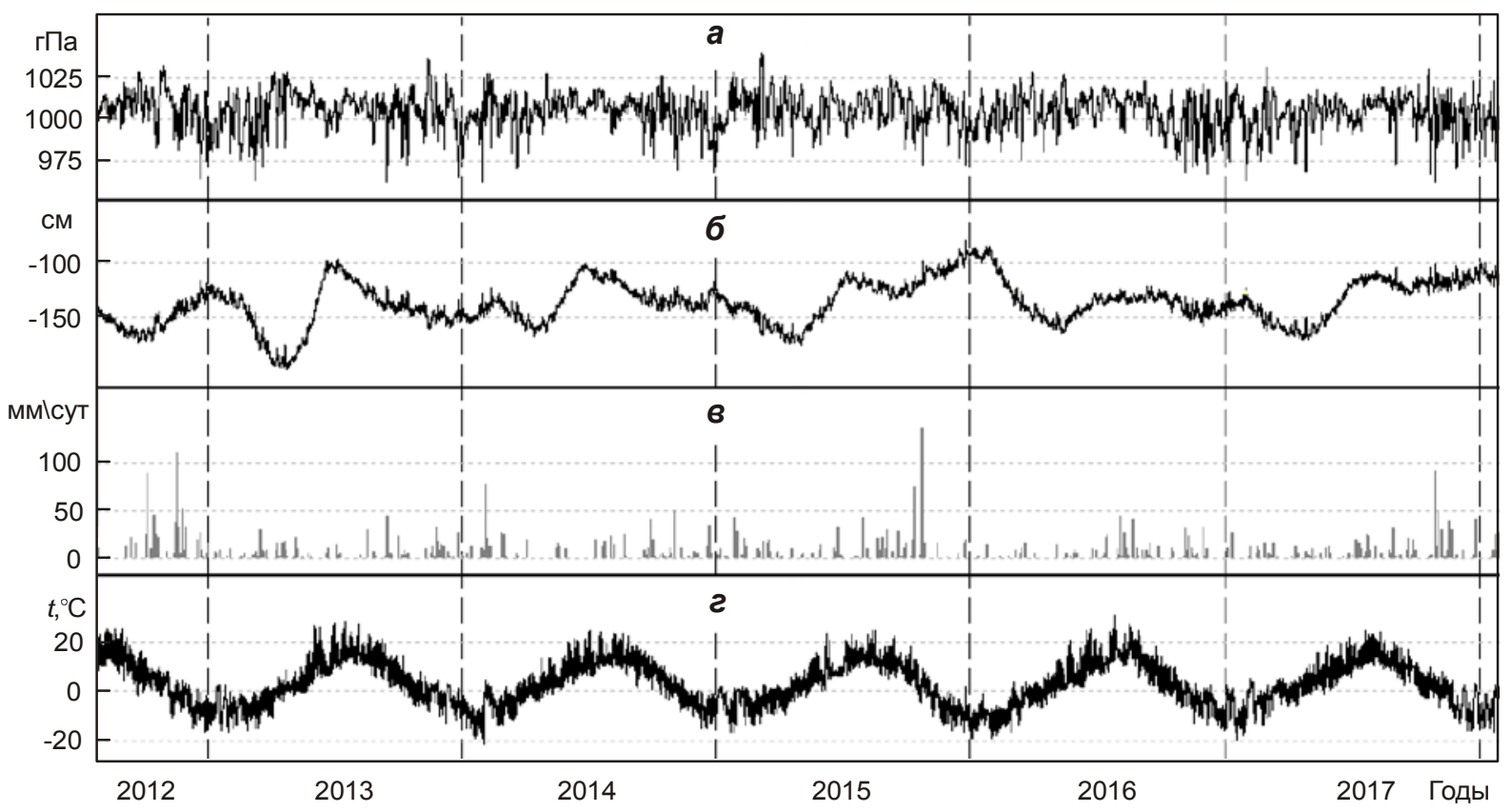

Рис. 1. Данные 5-минутных наблюдений за вариациями атмосферного давления $(a)$ и уровня воды в скважине Ю3-5 (б) с 27.07.2012 г. по 01.02.2018 г. в сопоставлении с изменениями температуры воздуха (2) и осадками (в) по данным метеостанции Пионерская Камчатского управления по гидрометеорологии и контролю состояния окружающей среды

Во время наблюдений скважина посещалась 32 раза. В пяти случаях проводились работы по извлечению и установке датчиков регистрации параметров подземных вод в верхней части ствола скважины. Такие работы проводились 16.04.2014 г. и 05.06.2014 г. (извлечение и установка зонда для измерений температуры и электропроводности воды на глубине 20 м), 01.03.2016 г. (подъем и спуск датчика уровня воды), 07.08.2017 г. (установка дополнительного датчика давления воды на глубине 5.6 м) и 04.10.2017 г. (неоднократный подъем и спуск датчика уровня воды с амплитудой $\approx 20$ см). Такие технические мероприятия сопровождались изменениями уровня воды, проявляющимися в его повышении или понижении с амплитудами 1-2 см с последующим восстановлением стационарного режима в течение 6-8 ч.

Сильные местные землетрясения и гидрогеосейсмические вариачии уровня воды. Рассматриваемый интервал времени примечателен не только высоким качеством данных уровнемерных наблюдений, но и тем, что включает пять землетрясений с магнитудами $M_{w}=6.5-8.3$, произошедших в Камчатской сейсмоактивной зоне и в западной части Алеутской сейсмоактивной зоны на эпицентральных расстояниях $d_{e}=80-700$ км (см. таблицу). Описание событий 1-3, произошедших в 2013 г., приводится в книге [Сильные..., 2014]. В работе [Чебров и др., 2016] представлены данные о Жупановском землетрясении, в [Чебров и др., 2017]-о Ближне-Алеутском землетрясении. В районе скважины указанные землетрясения сопровождались сотрясениями интенсивностью от 5 до 2-3 баллов по шкале MSK-64 [Медведев и др., 1965]. В связи с этими землетрясениями в скважине Ю3-5 проявлялись разнообразные гидрогеосейсмические вариации уровня воды. События 1, 2, 4 и 5 (таблица) сопровождались косейсмическими эффектами в течение первых минут после образования разрывов в очагах, а также более длительными постсейсмическими изменениями уровня воды. Перед событием 4 (см. таблицу) ретроспективно был выделен ГП в форме повышения уровня воды с амплитудой 28 см в течение 3.5 мес. [Болдина, Копьлова, 2017]. 
Параметры сильных землетрясений по данным КФ ФИЦ ЕГС РАН (http://www.emsd.ru/),

Global CMT (http://www.globalcmt.org), NEIS (US GS)

(https://earthquake.usgs.gov/earthquakes/search/)

\begin{tabular}{|c|c|c|c|c|c|c|c|c|}
\hline \multirow{3}{*}{$\begin{array}{l}\text { № } \\
\text { П/ா }\end{array}$} & \multicolumn{5}{|c|}{ Гипоцентр } & \multirow{2}{*}{\multicolumn{2}{|c|}{$\begin{array}{c}\text { Энергетические } \\
\text { параметры }\end{array}$}} & \multirow{3}{*}{$\begin{array}{c}\text { Эпицентральное } \\
\text { расстояние, } d_{e} \text {, } \\
\text { км/интенсив- } \\
\text { ность сотрясе- } \\
\text { ний по шкале } \\
M S K-64 \\
\end{array}$} \\
\hline & \multirow{2}{*}{$\begin{array}{c}\text { Дата } \\
\text { дд.мм.гггг, } \\
\text { название зем- } \\
\text { летрясения }\end{array}$} & \multirow[b]{2}{*}{$\begin{array}{l}\text { Время } \\
\text { чч:мм }\end{array}$} & \multicolumn{2}{|c|}{ Координаты, ${ }^{\circ}$} & \multirow[b]{2}{*}{$\begin{array}{l}H, \\
\text { км }\end{array}$} & & & \\
\hline & & & с.ш. & в.д. & & $\begin{array}{c}\text { Класс } \\
K_{\mathrm{S}}\end{array}$ & $\begin{array}{c}\text { Магнитуда } \\
M_{w}\end{array}$ & \\
\hline 1 & 28.02.2013 г. & $14: 06$ & 50.67 & 157.77 & 61 & 15.2 & 6.8 & $260 / 4-5$ \\
\hline 2 & $\begin{array}{c}24.05 .2013 \text { г. } \\
\text { Охотоморское }\end{array}$ & $05: 45$ & 54.76 & 153.79 & 630 & 17.0 & 8.3 & $348 / 4$ \\
\hline 3 & 12.11.2013 г. & 07:04 & 54.63 & 162.45 & 72 & 15.0 & 6.5 & $300 / 3-4$ \\
\hline 4 & $\begin{array}{c}30.01 .2016 \text { г. } \\
\text { Жупановское }\end{array}$ & $03: 25$ & 53.85 & 159.04 & 180 & 15.7 & 7.2 & $80 / 5$ \\
\hline 5 & $\begin{array}{c}17.07 .2017 \text { г. } \\
\text { Ближне- } \\
\text { Алеутское }\end{array}$ & $23: 34$ & 54.35 & 168.90 & 7 & 16.1 & 7.8 & $700 / 2-3$ \\
\hline
\end{tabular}

\section{Компенсация баровариаций в изменениях уровня воды и спектры мощности}

Изменение атмосферного давления является основным метеорологическим фактором, влияющим на вариации уровня воды в скважине Ю3-5 в диапазоне часовыхсуточных периодов (см. рис. 1). Ранее по поведению амплитудной передаточной функции от вариаций атмосферного давления к изменениям уровня воды было установлено, что барометрический отклик уровня характеризуется постоянной величиной барометрической эффективности $E_{b}=0.4 \mathrm{~cm} / \Gamma П а$ в диапазоне периодов от 6 ч до первых десятков суток. На периодах от 2 до 6 ч величина $E_{b}$ монотонно возрастает от 0.1 до $0.4 \mathrm{~cm} / \Gamma$ Па [Копьлова, 2006а, 2009].

Перед выполнением статистического анализа данных уровнемерных наблюдений необходимо “очистить” исходный временной ряд уровня воды от влияния атмосферного давления. Для этой операции применялся компенсирующий адаптивный частотный фильтр [Любушин, 2007]. В скользящих временных окнах длиной 28 сут или 8064 отсчетов с шагом 5 мин, взятых с минимальным смещением 1 отсчет, вычислялись спектр мощности $S_{u u}(\omega)$ атмосферного давления и комплексный кросс-спектр $S_{x u}(\omega)$ между уровнем воды и давлением в зависимости от частоты $\omega$. Такие оценки получаются путем сглаживания периодограмм и кросс-периодограмм частотным окном длиной $1 / 32$ от длины окна. Далее в каждом окне вычислялась частотная передаточная функция $H_{x u}(\omega)=S_{u u}(\omega) / S_{u u}(\omega)$. При этом перед сглаживанием периодограмм подавлялись приливные частотные полосы $[1 / 11,1 / 13]$ и $[1 / 23,1 / 27] \mathrm{ч}^{-1}$, а оценки внутри этих частотных полос получались интерполяцией оценок от соседних значений частот. Результат компенсации $\tilde{E}_{x}(\omega)$ в частотной области внутри каждого временного окна вычислялся по формуле $\tilde{E}_{x}(\omega)=\tilde{X}(\omega)-H_{x u}(\omega) \tilde{U}(\omega)$, где $(\tilde{X}(\omega), \tilde{U}(\omega))$ - дискретные преобразования Фурье от уровня подземных вод и атмосферного давления внутри текущего окна. Результат компенсации $e_{x}(t)$ во временной области внутри каждого временного окна определяется обратным дискретным преобразованием Фурье от $\tilde{E}_{x}(\omega)$. 
Заключительной операцией получения компенсированного сигнала является сшивка внутриоконных результатов компенсации в один сигнал. Для первого окна вкладом в такой единый сигнал является содержимое части временного окна, соответствующее первой половине окна, а для последнего окна - соответствующее второй половине. Что же касается прочих, “промежуточных" временных окон, то из них в единый компенсированный сигнал берется лишь один отсчет, соответствующий центру окна,

На рис. 2 представлены графики исходного и компенсированного уровня воды (далее - ряд $\left.U_{k}(t)\right)$ для первой половины 2013 г., когда произошли сейсмические события 1 и 2 (см. таблицу). Видно, насколько более четко выделяются приливные (рис. 2,8$)$, ко- и постсейсмические вариации уровня в компенсированном сигнале $U_{k}(t)$ (рис. 2, б) по сравнению с исходными данными (рис. 2, a), где они “тонут” в вариациях, обусловленных в основном влиянием атмосферного давления.

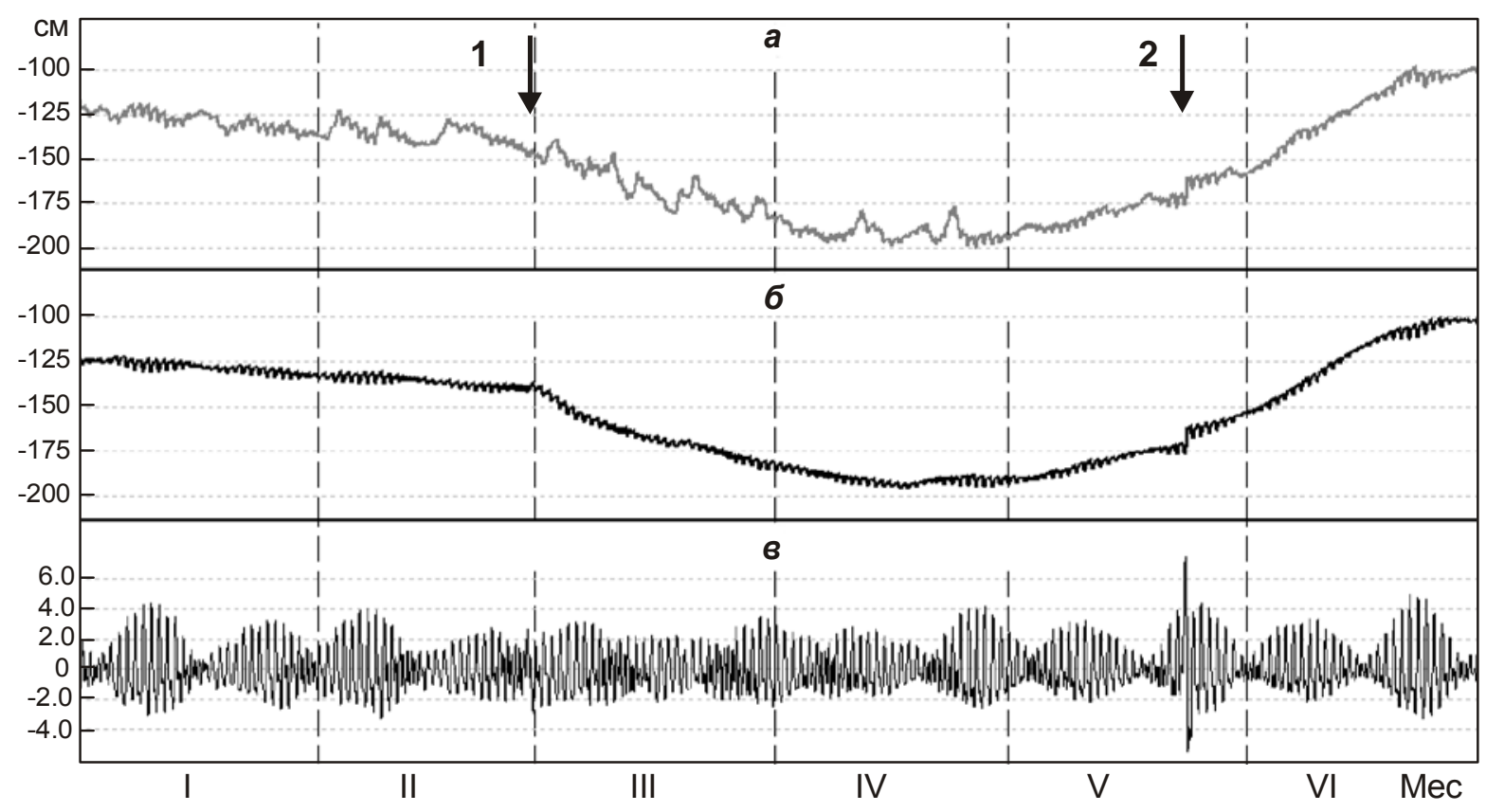

Рис. 2. Изменения уровня воды в скважине ЮЗ-5 в январе-июне 2013 г.: $a$-исходные данные 5 -минутной регистрации; $\sigma$ - данные после компенсации баровариаций (ряд $\left.U_{k}(t)\right) ; 8$ - приливные вариации. Стрелками показаны землетрясения, цифры - номера землетрясений по таблице

На рис. 3 приведены оценки спектра мощности вариаций исходного временного ряда уровня воды и ряда $U_{k}(t)$. На рис. $3, a$ видно яркое проявление приливных гармоник полусуточной и суточной групп. В диапазоне приливных периодов в спектре мощности ряда $U_{k}(t)$ четко выделяются 9 приливных волн (рис. 3, б). При этом слабовыраженные спектральные пики на периодах, соответствующих высшим обертонам суточного колебания $-6,4,2$ ч, после компенсации баровариаций сохранились. Эти обертоны возникают как следствие неравномерного во времени нагревания и охлаждения воздуха в течение суток и отличия суточного хода температуры от чисто синусоидальной формы. Такие изменения температуры оказывают влияние на атмосферное давление и сопровождаются соответствующими откликами уровня воды. Также следует отметить выпрямление графика спектра мощности (в двойном логарифмическом масштабе): после компенсации баровариаций полностью исчез “горб” на спектре мощности для периодов от 10 до 1000 ч. 

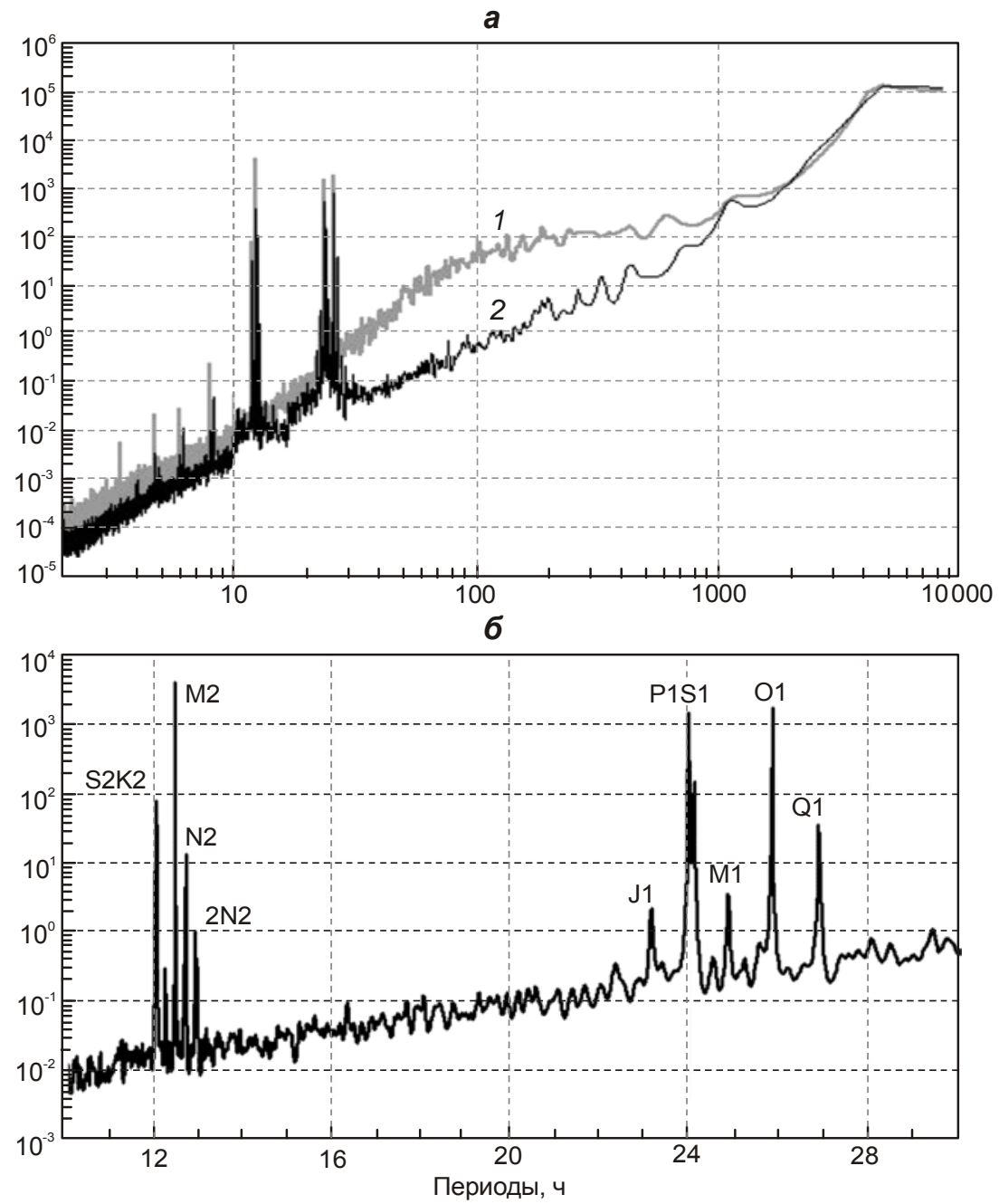

Рис. 3. Спектры мощности вариаций уровня воды в скважине Ю3-5: $a$ - исходного 5-минутного временного ряда $(1)$ и компенсированного временного ряда $U_{k}(t)(2) ; \sigma$-вариаций ряда $U_{k}(t)$ в диапазоне проявления приливных волн суточной группы (J1, P1S1, M1, O1, Q1) и полусуточной группы (S2K2, M2, N2, 2N2). Названия приливных волн даны по [Мельхиор, 1968]

\section{Статистические свойства временного ряда компенсированного уровня воды $U_{k}(t)$}

План дальнейшего анализа состоит в том, чтобы оценить набор статистических свойств, описывающих поведение временного ряда уровня $U_{k}(t)$ в последовательных временных фрагментах, и использовать полученные значения для выделения его различных состояний. Длина временного фрагмента была выбрана $N=288$ отсчетов, что составляет 1 сут при шаге по времени 5 мин.

Ниже дается краткое описание восьми используемых статистик. Выбор этих статистик производился с учетом опыта их использования для анализа других временных рядов систем мониторинга, причем не только геофизических (ниже приводятся соответствующие ссылки). Следует отметить, что эти статистики не привязаны к физической природе анализируемых сигналов. Они имеют характер описания самых общих свойств временного ряда, таких как энтропия, степень отличия от хаотического поведения, предсказуемость, степень нестационарности поведения, форма спектра мощности и пр. Все оценки производились для временного ряда приращений компенсированного уровня подземных вод $U_{k}(t)$ после применения к нему процедуры винзоризации (winsorizing) 
[Huber, Ronchetti, 2009] в интервале $\pm 3 \sigma$ (далее - ряд $x(t))$ для обеспечения устойчивости (робастности) получаемых статистических оценок к различного рода выбросам.

Минимальная нормализованная энтропия вейвлет-коэффициентов En. Пусть $x(t)$ - конечная выборка некоторого случайного сигнала, $t=1, \ldots, N$-индекс, нумерующий последовательные отсчеты (дискретное время). Пусть $c_{j}^{(k)}$ - вейвлет-коэффициенты анализируемого сигнала. Верхний индекс $k$ является номером уровня детальности ортогонального вейвлет-разложения, нижний индекс $j$ нумерует последовательность центров временных интервалов, в окрестности которых вычисляется свертка сигнала $c$ финитными элементами базиса. Использовались 17 ортогональных вейвлетов Добеши: 10 обычных базисов с минимальным носителем с числом обнуляемых моментов от 1 до 10 и 7 симлетов Добеши [Малла, 2005] с числом обнуляемых моментов от 4 до 10. Для каждого из базисов вычислялась нормализованная энтропия распределения квадратов коэффициентов и находился базис, обеспечивающий минимум энтропии:

$$
E n=-\sum_{k=1}^{m} \sum_{j=1}^{M_{k}} p_{j}^{(k)} \ln p_{j}^{(k)} / \ln N_{r} \rightarrow \min , p_{j}^{(k)}=\left|c_{j}^{(k)}\right|^{2} / \sum_{l, i}\left|c_{i}^{(l)}\right|^{2},
$$

где $m$ - число уровней детальности, принятых к рассмотрению; $M_{k}$-число вейвлеткоэффициентов на уровне детальности с номером $k$. Число уровней $m$ зависит от длины $N$ анализируемой выборки. Например, если $N=2^{n}$, то $m=n, M_{k}=2^{(n-k)}$. Условие $N=2^{n}$ необходимо для применения быстрого вейвлет-преобразования. Если длина $N$ не равна степени двойки, то сигнал $x(t)$ дополняется нулями до минимальной длины $L$, которая больше или равна $N$ : $L=2^{n} \geq N$. В этом случае среди числа $2^{(n-k)}$ всех вейвлеткоэффициентов на уровне $k$ лишь $N \cdot 2^{-k}$ коэффициентов соответствуют разложению реального сигнала, тогда как остальные коэффициенты равны нулю из-за дополнения нулями сигнала $x(t)$. Таким образом, в формуле (1) $M_{k}=N \cdot 2^{-k}$ и для вычисления энтропии используются только “реальные” коэффициенты $c_{j}^{(k)}$. Число $N_{r}$ в формуле (1) равно числу “реальных" коэффициентов, то есть $N_{r}=\sum_{k=1}^{m} M_{k}$. По построению $0 \leq E n \leq 1$. Статистика En использовалась в работах [Lyubushin, 2012; Любушин, 2014] при исследовании прогностических свойств сейсмического шума на Японских островах.

Индекс Донохо-Джонстона $\gamma$. После того, как для данного сигнала определен вейвлет-базис из условия минимума энтропии, мы можем определить набор вейвлеткоэффициентов, которые являются наименьшими по модулю. В вейвлет-фильтрации эти вейвлет-коэффициенты могут быть обнулены перед обратным вейвлетпреобразованием с целью “уменьшения шума" [Donoho, Johnstone, 1995; Maлла, 2005]. Мы предполагаем, что шум концентрируется в основном в вариациях на первом уровне детальности. Напомним, что первый уровень детальности соответствует самым высокочастотным вариациям временного ряда с периодами от $2 \Delta t$ до $4 \Delta t$, где $\Delta t-$ шаг дискретизации по времени. Из-за ортогональности вейвлет-преобразования дисперсия вейвлет-коэффициентов равна дисперсии исходного сигнала. Таким образом, мы оцениваем стандартное отклонение шума как стандартное отклонение вейвлеткоэффициентов на первом уровне детализации. Эта оценка должна быть устойчивой, т.е. нечувствительной к выбросам в значениях вейвлет-коэффициентов на первом уровне. Для этого мы можем использовать робастную медианную оценку стандартного отклонения для нормальной случайной величины:

$$
\sigma=\operatorname{med}\left\{\left|c_{k}^{(1)}\right|, k=1, \ldots, N / 2\right\} / 0.6745,
$$

где $c_{k}^{(1)}$ - вейвлет-коэффициенты на первом уровне детальности; $N / 2$ - число таких коэффициентов. Оценка стандартного отклонения $\sigma$ из формулы (2) определяет величину $\sigma \sqrt{2 \cdot \ln N}$ как “естественный” порог для выделения шумовых вейвлет-коэффициентов. 
Величина $\sigma \sqrt{2 \cdot \ln N}$ известна в вейвлет-анализе как порог Донохо-Джонстона, а само выражение для этой величины основано на формуле для асимптотической вероятности максимальных уклонений гауссовского белого шума [Малла, 2005]. В результате можно определить безразмерную характеристику сигнала $\gamma, 0<\gamma<1$ как отношение числа наиболее информативных вейвлет-коэффициентов, для которых выполнено неравенство $\left|c_{k}\right|>\sigma \sqrt{2 \cdot \ln N}$, к общему числу $N$ всех вейвлет-коэффициентов. Формально чем больше индекс $\gamma$, тем более информативным (менее “шумовым”) является сигнал.

Вейвлетная спектральная экспонента $\beta$. Для оптимального ортогонального вейвлета можно вычислить средние значения квадратов вейвлет-коэффициентов на каждом уровне детальности: $S_{k}=\sum_{j=1}^{M_{k}}\left|c_{j}^{(k)}\right|^{2} / M_{k}$. Среднее значение квадратов вейвлеткоэффициентов является частью энергии колебаний, соответствующей уровню детальности $k$. Иными словами, эта величина может быть рассмотрена как оценка спектра мощности сигнала $x(t)$ в полосе частот, соответствующих уровню детальности $k$ [Малла, 2005]: $\left[f_{\min }{ }^{(k)}, f_{\max }{ }^{(k)}\right]=\left[1 /\left(2^{(k+1)} \Delta s\right), 1 /\left(2^{k} \Delta s\right)\right]$, где $\Delta s$ - длина временного интервала дискретизации (в нашем случае $\Delta s=5$ мин). Значения периодов, соответствующих центрам частотных полос, равны $T_{k}=2 /\left(f_{\min }{ }^{(k)}+f_{\max }{ }^{(k)}\right)=2 \Delta s /\left(2^{-k}+2^{-(k+1)}\right)$. Величины $S_{k}=S\left(T_{k}\right)$, $k=1, \ldots, m$ аналогичны обычным Фурье-спектрам мощности. Отличие заключается в том, что величины $S_{k}$ гораздо более гладкие, что удобно при вычислении спектральной экспоненты - наклона графика логарифма спектра мощности в зависимости от логарифма периода. Для вычисления спектральной экспоненты рассмотрим модель $\ln \left(S\left(T_{k}\right)\right)$ $=\beta \cdot \ln \left(T_{k}\right)+c+\varepsilon_{k}$, где $\varepsilon_{k}-$ последовательность независимых случайных величин с нулевым средним. Параметр $\beta$ можно назвать вейвлетной спектральной экспонентой, значение которой может быть найдено методом наименьших квадратов: $\sum_{k=1}^{m} \varepsilon_{k}^{2} \rightarrow \min _{\beta, c}$.

Модель авторегрессии. Далее будет использоваться модель авторегрессии [Box, Jenkins, 1970; Kashyap, Rao, 1976] для временного ряда $x(t)$. Запишем ее в общей форме:

$$
x(t)+\sum_{k=1}^{p} a_{k}^{(p)} x(t-k)=e^{(p)}(t)+d^{(p)} .
$$

Здесь целое число $p \geq 1$ - порядок авторегрессии, вектор $c=\left(a_{1}{ }^{(p)}, \ldots, a_{p}{ }^{(p)}, d^{(p)}\right)^{T}$ является вектором неизвестных параметров. Верхний индекс $(p)$ в формуле (3) подчеркивает, что используется модель авторегрессии $p$-го порядка. Здесь $a_{k}^{(p)}-$ коэффициенты авторегрессии, $d^{(p)}$-параметр статического смещения, $e^{(p)}(t)$ - остаточный сигнал с нулевым средним и дисперсией $\sigma_{p}^{2}$. Модель (3) можно записать в компактной форме:

$$
x(t)=c^{T} Y(t)+e^{(p)}(t), \quad Y(t)=(-x(t-1), \ldots,-x(t-p), 1)^{T} .
$$

Пусть имеется конечная выборка $\{x(t), t=1, \ldots, N\}$. Тогда оценка вектора параметров $c$ из условия минимума суммы квадратов остатков $\sum_{t=p+1}^{N}\left(e^{(p)}(t)\right)^{2} \rightarrow \min _{c}$ сводится к решению системы нормальных уравнений с симметричной положительно определенной матрицей $A$ :

$$
A c=R, A=\sum_{t=p+1}^{N} Y(t) Y^{T}(t), R=\sum_{t=p+1}^{N} x(t) Y(t) .
$$

Полный вектор параметров модели (4) есть $\theta^{(p)}=\left(c^{T}, \sigma_{p}\right)^{T}$.

Далее в качестве характеристик фрагментов временного ряда, наряду с прочими параметрами, будут использованы значения коэффициента $a_{1}^{(1)}$ модели авторегрессии первого порядка и логарифм дисперсии остатка в этой модели $\lg \sigma_{1}^{2}$. 


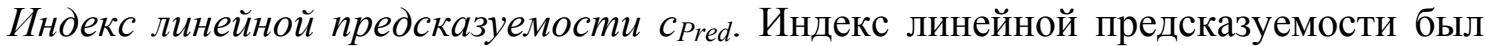
введен в работе [Любушин, 2010], см. также [Lyubushin, 2012]. Рассмотрим величину $c_{\text {Pred }}=V_{0} / V_{A R}-1$. Здесь $V_{0}-$ дисперсия ошибки $\varepsilon_{0}(t+1)$ тривиального прогноза $\hat{x}_{0}(t+1)$ на один шаг вперед для сигнала $x(t)$, который равен среднему по предыдущему “малому" временному окну длиной $n$ отсчетов: $\hat{x}_{0}(t+1)=\sum_{s=t-n+1}^{t} x(t) / n$. Таким образом, $\varepsilon_{0}(t+1)=x(t+1)-\hat{x}_{0}(t+1)$, а $V_{0}=\sum_{t=n+1}^{N} \varepsilon_{0}^{2}(t) /(N-n)$, где $N>n-$ число отсчетов в последовательных “больших” временных фрагментах. Величина $V_{A R}$ вычисляется по аналогичной формуле $V_{A R}=\sum_{t=n+1}^{N} \varepsilon_{A R}^{2}(t) /(N-n)$, в которой $\varepsilon_{A R}(t+1)=x(t+1)-\hat{x}_{A R}(t+1)-$ ошибка линейного прогноза $\hat{x}_{A R}(t+1)$ на 1 шаг вперед с помощью модели авторегрессии 2-го порядка, коэффициенты которой оцениваются также по предыдущему “малому” временному окну длиной $n$ отсчетов.

Выбор 2-го порядка авторегрессии обусловлен тем, что это минимальный для $A R$-модели порядок, при котором описывается колебательное движение и допускается положение максимума спектральной плотности модели авторегрессии в значениях частот между частотой Найквиста и нулевой. $A R$-прогноз использует свойство коррелированности соседних значений и, если коррелированность имеет место, то $V_{A R}<V_{0}$ и $c_{\text {Pred }}>0$. При длине “большого" временного окна $N=288$ длина малого окна бралась равной $n=48$.

Авторегрессионная мера нестационарности сигнала $R^{2}$. Пусть $x(t)$ - изучаемый сигнал, $n$ - половина длины скользящего временного окна, которое далее будем называть “коротким”. Пусть $\tau$ - центр двойного скользящего временного окна, в которое, тем самым, входят временные отсчеты $t$, удовлетворяющие условию $\tau-n \leq t \leq \tau+n$. Для левой и правой половин короткого окна построим скалярную авторегрессионную модель (5) порядка $p=2$ для сигнала $x(t)$. Оценивая модель независимо по выборкам, попавшим в левую и правую половины двойного скользящего временного окна, получим два вектора параметров $\theta_{1}{ }^{(p)}$ и $\theta_{2}{ }^{(p)}$ соответственно. Обозначим как $\Delta \theta=\theta_{1}{ }^{(p)}-\theta_{2}{ }^{(p)}$ разницу между векторами оценок на правой и левой половинах скользящего временного окна.

Если поведение изучаемого сигнала на левой и правой половинах сильно различается, то будет увеличиваться разница $\Delta \theta$. Для “взвешивания” вектора $\Delta \theta$ в качестве метрической матрицы логично использовать матрицу Фишера, поскольку она определяет скорость изменения логарифмической функции правдоподобия в окрестности точки максимума по параметрам матрицы вторых производных от условной логарифмической функции правдоподобия авторегрессионной модели:

$$
B=-\frac{\partial^{2} \ln \Phi}{\partial \theta \partial \theta}, \quad \ln \Phi=-(n-p) \ln \sigma_{p}-\frac{1}{2 \sigma_{p}^{2}} \sum_{t}\left(x(t)-c^{T} Y(t)\right)^{2} .
$$

Обозначим через $B^{(1)}$ и $B^{(2)}$ матрицы, вычисленные по левой и правой половинам скользящего окна соответственно. Тогда мерой нестационарности поведения процесса $x(t)$ в симметричной окрестности точки $\tau$ будет величина:

$$
r^{2}(\tau)=\left(\Delta \theta^{T} B^{(1)} \Delta \theta+\Delta \theta^{T} B^{(2)} \Delta \theta\right) / 2(n-p) .
$$

В формуле (7) полусумма длин вектора разности параметров $\Delta \theta$, измеряемых с помощью метрических матриц $B^{(1)}$ и $B^{(2)}$, делится на $(n-p)$ - число отсчетов в левой 
и правой частях скользящего окна за вычетом числа авторегрессионных параметров. Такая метрика обеспечивает естественную безразмерную меру нестационарности поведения исследуемого сигнала. Проведя несложные выкладки, нетрудно получить следующее выражение:

$$
\Delta \theta^{T} B \Delta \theta=\frac{2\left(\Delta \sigma_{p}\right)^{2}}{\sigma_{p}^{2}}+\frac{\Delta c^{T}\left(\sum_{t} Y(t) Y^{T}(t)\right) \Delta c}{\sigma_{p}^{2}(n-p)}+\frac{4 \Delta c^{T} \Delta \sigma_{p} \sum_{t} e^{(p)}(t) Y(t)}{\sigma_{p}^{3}(n-p)},
$$

полезное при вычислении значения меры нестационарности (7). Мера нестационарного поведения была введена в работе [Любушин и др., 1999], см. также [Любушин, 2007]. В работах [Osorio et al., 2011; Любушин, Фарков, 2017] статистика (7) была использована для анализа электроэнцефалограмм при исследовании эпилепсии и для анализа финансовых временных рядов.

Используя формулы (7)-(8), можно определить другую, более устойчивую меру нестационарного поведения исследуемого сигнала внутри “длинного" временного интервала, состоящего из $N$ последовательных отсчетов. Для этого возьмем “короткое" окно радиуса $n$ отсчетов, $2 n+1<N$, и вычислим меру нестационарного поведения $r^{2}(\tau)$ для всех возможных положений центральной точки $\tau$ внутри “длинного” окна, при которых “короткое” окно целиком лежит внутри “длинного". Нетрудно посчитать, что число таких допустимых положений центральной точки $\tau$ равно $N-2 n$. Определим интегральную меру нестационарности $R^{2}$ для “длинного” окна как медиану значений $r^{2}(\tau)$ для всех допустимых положений центральной точки $\tau$ “короткого” окна внутри “длинного”. В вычислениях мы использовали длины окон $N=288$ и $n=48$. В дальнейшем мы будем рассматривать логарифм меры нестационарности $\lg R^{2}$.

Коэффицичент эксиесса к определяется формулой $\kappa=M\left(x^{4}\right) /\left(M\left(x^{2}\right)\right)^{2} \quad[$ Cramer, 1999]. Коэффициент эксцесса характеризует “остроту” графика плотности вероятности распределения случайной величины $x$ с нулевым средним и дает меру отклонения плотности вероятности от нормального закона, для которого к=3. Здесь операция $M(. .$. означает вычисление математического ожидания, в данном случае просто выборочного среднего случайной величины. Обычно под коэффициентом эксцесса понимается введенная выше величина к, из которой вычитается 3 , чтобы для нормального закона эксцесс был равен нулю. Однако далее мы будем рассматривать логарифм эксцесса $\operatorname{lg\kappa ,~}$ поэтому значение 3 не вычитается, чтобы гарантировать положительные значения этого логарифма.

Итак, для каждого суточного временного окна имеется 8 параметров, характеризующих различные статистические свойства временного ряда $U_{k}(t)$ внутри этого окна: минимальная нормированная энтропия вейвлет-коэффициентов $E n$, индекс ДонохоДжонстона $\gamma$, коэффициент $a_{1}{ }^{(1)}$ и логарифм дисперсии $\lg \sigma_{1}^{2}$ в модели авторегрессии 1-го порядка, индекс линейной предсказуемости $c_{\text {Pred }}$ и логарифм меры нестационарности $\lg R^{2}$, основанные на использовании модели авторегрессии 2-го порядка, вейвлетная спектральная экспонента $\beta$ и логарифм коэффициента эксцесса $\operatorname{lg\kappa .~}$

Восьмимерный вектор параметров, характеризующих статистические свойства временного ряда приращений $U_{k}(t)$ внутри последовательных временных фрагментов диной 1 сут (288 отсчетов с шагом по времени 5 мин), обозначим

$$
\zeta=\left(E n, \gamma, a_{1}^{(1)}, \lg \sigma_{1}^{2}, c_{\text {Pred }}, \lg R^{2}, \beta, \lg \kappa\right) .
$$

На рис. 4 представлены графики изменения отдельных компонент 8-мерного вектора $\zeta$ свойств ряда приращений $U_{k}(t)$ в зависимости от положения правого конца последовательных временных окон длиной 1 сут. 

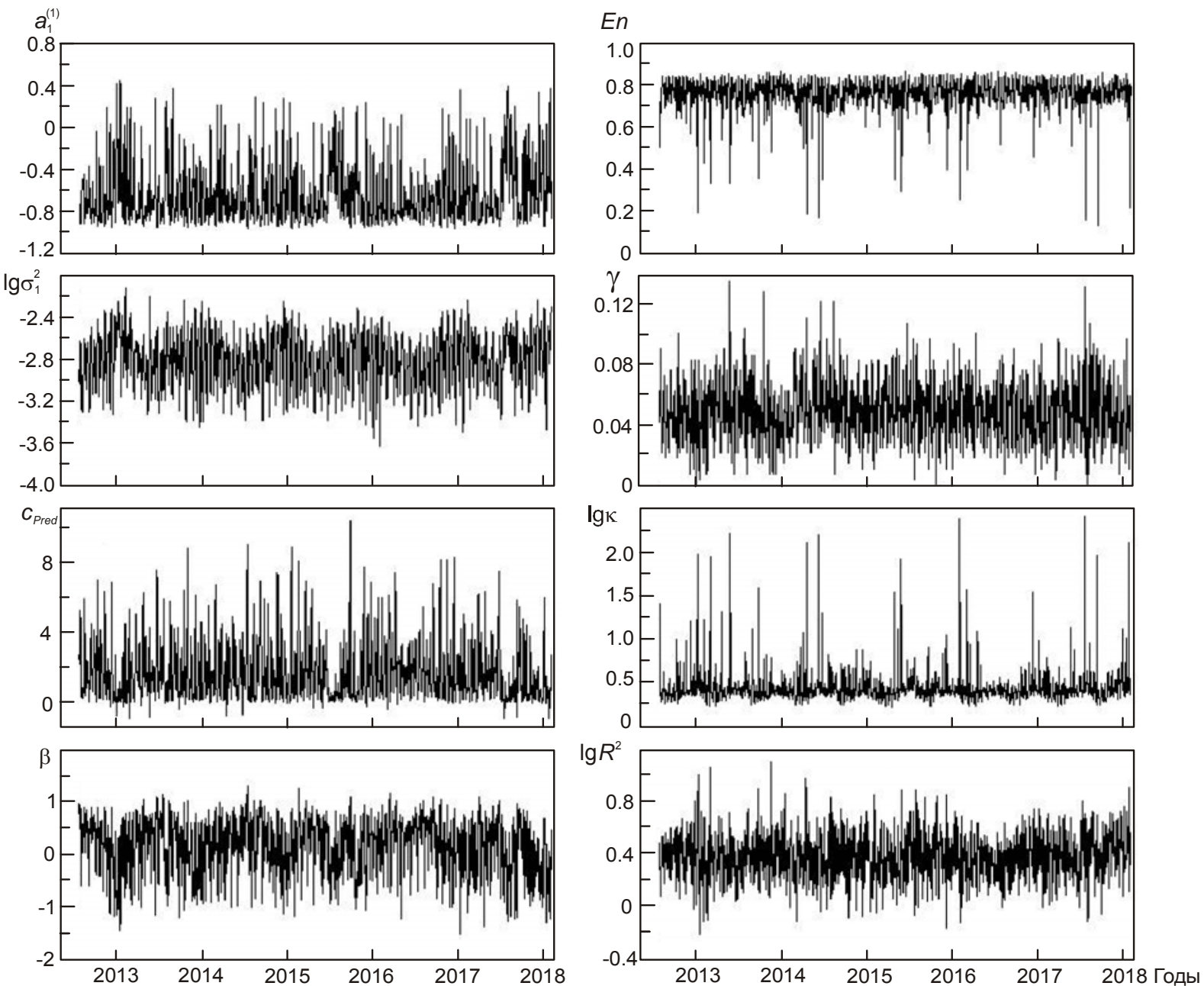

Рис. 4. Графики восьми свойств временного ряда приращений уровня подземных вод после компенсации влияния атмосферного давления $U_{k}(t)$ в последовательных окнах длиной 1 сут

\section{Факторный анализ вектора свойств временного ряда}

Сделаем попытку выделить различные состояния в истории временного ряда наблюдений за уровнем подземных вод, используя кластерный анализ 8-мерного вектора признаков (9). Для формального разбиения полученного облака векторов $\zeta$ на кластеры предварительно выполним операцию понижения размерности с помощью факторного анализа. Модель факторного анализа [Harman, 1967] в рассматриваемом случае описывается формулой:

$$
z=\Lambda \cdot f+e,
$$

где 8-мерный вектор $z$ получается из вектора $\zeta$ операцией нормировки, которая заключается в удалении выборочного среднего и делении на выборочную оценку стандартного отклонения для каждой компоненты вектора $\zeta$. После выполнения операции нормировки вычисляется корреляционная матрица $\mathrm{R}_{z z}$.

В формуле (10) $f$ - вектор размерности $q<p=8$, состоящий из скрытых факторов некоторых случайных векторов, которые “управляют" значениями скалярных компонент многомерного вектора $z$ посредством умножения на матрицу факторных нагрузок $\Lambda$ размером $p$ строк на $q$ столбцов. Элементы матрицы $\Lambda=\left(\lambda_{j a}\right), j=1, \ldots, p ; a=1, \ldots, q$ являются неизвестными параметрами модели, которые необходимо определить, имея 
выборочную оценку корреляционной матрицы $\mathrm{R}_{z z}$ исходных данных. Будем считать, что число скрытых параметров $q$ известно. Относительно свойств случайного вектора $f$ предполагается, что его среднее равно нулю, $M\{f\}=0$, а его ковариационная матрица единична: $M\left\{f \cdot f^{\mathrm{T}}\right\}=I_{q}$, где $I_{q}-q$-мерная единичная матрица.

Это условие означает ортогональность факторов (их независимость в гауссовском случае). Условие равенства единице дисперсий ортогональных факторов является своего рода нормировкой, так как в противном случае этого можно добиться масштабированием элементов матрицы $\Lambda$. Вектор $e$ в формуле (10) имеет ту же размерность, что и исходный вектор $z$, и состоит из случайных величин, описывающих шум по каждой из компонент вектора $z$, т.е. не несущих полезной информации. Так как шумы по различным компонентам должны быть независимы, то относительно вектора $e$ предполагается, что он центрирован и его ковариационная матрица имеет диагональный вид: $M\left\{e \cdot e^{T}\right\}=\Psi^{2}=\operatorname{diag}\left\{\Psi_{1}^{2}, \ldots, \Psi_{p}^{2}\right\}$, где $\Psi_{j}^{2}, j=1, \ldots, p$ - так называемые остаточные дисперсии или дисперсии шумов. Элементы диагональной матрицы $\Psi^{2}$ также являются параметрами модели (10).

Наиболее надежным и простым способом идентификации параметров модели (10) является метод минимальных остатков [Harman, 1967]. Из условий диагональности ковариационных матриц векторов $f$ и $e$ нетрудно получить, что в силу модели (10) ковариационная матрица вектора $z$ равна

$$
\Sigma=M\left\{z \cdot z^{T}\right\}=\Lambda \cdot \Lambda^{T}+\Psi^{2} .
$$

Метод минимальных остатков заключается в определении элементов матрицы $\Lambda$ из условия минимума суммы квадратов разностей между выборочными оценками и теоретическими значениями попарных коэффициентов корреляции. Тем самым, критерием близости модели к данным является близость всех теоретических коэффициентов корреляции их выборочным оценкам. Обозначим через $r_{i j}$ элементы матрицы $\mathrm{R}_{\mathrm{zz}}$. Тогда необходимо минимизировать следующую функцию от элементов матрицы факторных нагрузок:

$$
\Phi(\Lambda)=\sum_{j=1}^{p-1} \sum_{i=j+1}^{p}\left(r_{i j}-\sum_{\alpha=1}^{q} \lambda_{j \alpha} \lambda_{i \alpha}\right)^{2} \rightarrow \min _{\Lambda} .
$$

При этом на элементы матрицы $\Lambda$ должны быть наложены ограничения:

$$
\sum_{\alpha=1}^{q} \lambda_{j \alpha}^{2} \leq 1, j=1, \ldots, p
$$

вытекающие из условия равенства единице диагональных элементов теоретической матрицы корреляций (13). Стоит отметить, что задача определения матрицы $\Lambda$ независима от определения диагональной матрицы остаточных дисперсий $\Psi^{2}$. После того, как задача на минимум (12) при ограничениях (13) решена, остаточные дисперсии находятся автоматически:

$$
\psi_{j}^{2}=1-\sum_{\alpha=1}^{q} \lambda_{j \alpha}^{2}, \quad j=1, \ldots, p .
$$

После определения матрицы факторных нагрузок финальным шагом анализа является вычисление собственно реализаций ортогональных факторов - облака $q$-мерных векторов $f$. Наиболее простая оценка следует из условия, что вектор шумов $e$ распределен согласно $p$-мерному нормальному распределению с ковариационной матрицей $\Psi^{2}$. В этом случае оценкой максимального правдоподобия будет оценка взвешенного метода наименьших квадратов:

$$
e^{T} \cdot \Psi^{-2} \cdot e \rightarrow \min _{f}, f=\left(\Lambda^{T} \Psi^{-2} \Lambda\right)^{-1} \Lambda^{T} \Psi^{-2} \cdot z
$$


Однако оценка (15) дает вектор общих факторов с недиагональной ковариационной матрицей. Для того, чтобы компоненты вектора факторов были ортогональны, следует применять модификацию оценки (15), предложенную в [Anderson, Rubin, 1956]:

$$
f=\left(\Lambda^{T} \Psi^{-2} \Sigma \Psi^{-2} \Lambda\right)^{-1 / 2} \Lambda^{T} \Psi^{-2} \cdot z, \quad \Sigma=\Lambda \Lambda^{T}+\Psi^{2} .
$$

Целью получения реализаций вектора общих факторов $f$ является снижение размерности задачи [Айвазян $u$ дp., 1989]. Вопрос о выборе числа $q$ общих факторов - размерности вектора $f$ - самый трудный вопрос в факторном анализе. Для его решения был предложен критерий Риппе [Lawley, Maxwell, 1971], который опирается на предположение о нормальности распределения векторов $z$. Однако этот критерий показал сильную чувствительность к малым отклонениям от нормальности, что делает его практически неприменимым. Если отсутствует априорная информация о числе $q$, то можно получить оценку максимально допустимого числа общих факторов, начав решать задачу с минимального $q=1$ и постепенно увеличивая $q$ на единицу до тех пор, пока модель факторного анализа не выродится (общее число параметров станет избыточным). После этого можно взять в качестве $q$ последнее максимальное значение перед вырождением задачи. Вырождение задачи факторного анализа называется "случаем Хейвуда" [Harman, 1967] и заключается в обнулении остаточной дисперсии $\Psi_{j}^{2}$ для одного или нескольких компонент вектора $z$. Практически вместо обнуления наблюдается резкое уменьшение остаточной дисперсии для той или иной компоненты по сравнению с прочими (на несколько порядков).

Именно этот метод выбора $q$ использовался в нашем случае, и он определил максимальное допустимое значение числа общих ортогональных факторов $q=3$. На рис. 5 представлены графики трех общих ортогональных факторов F1, F2, F3 для множества

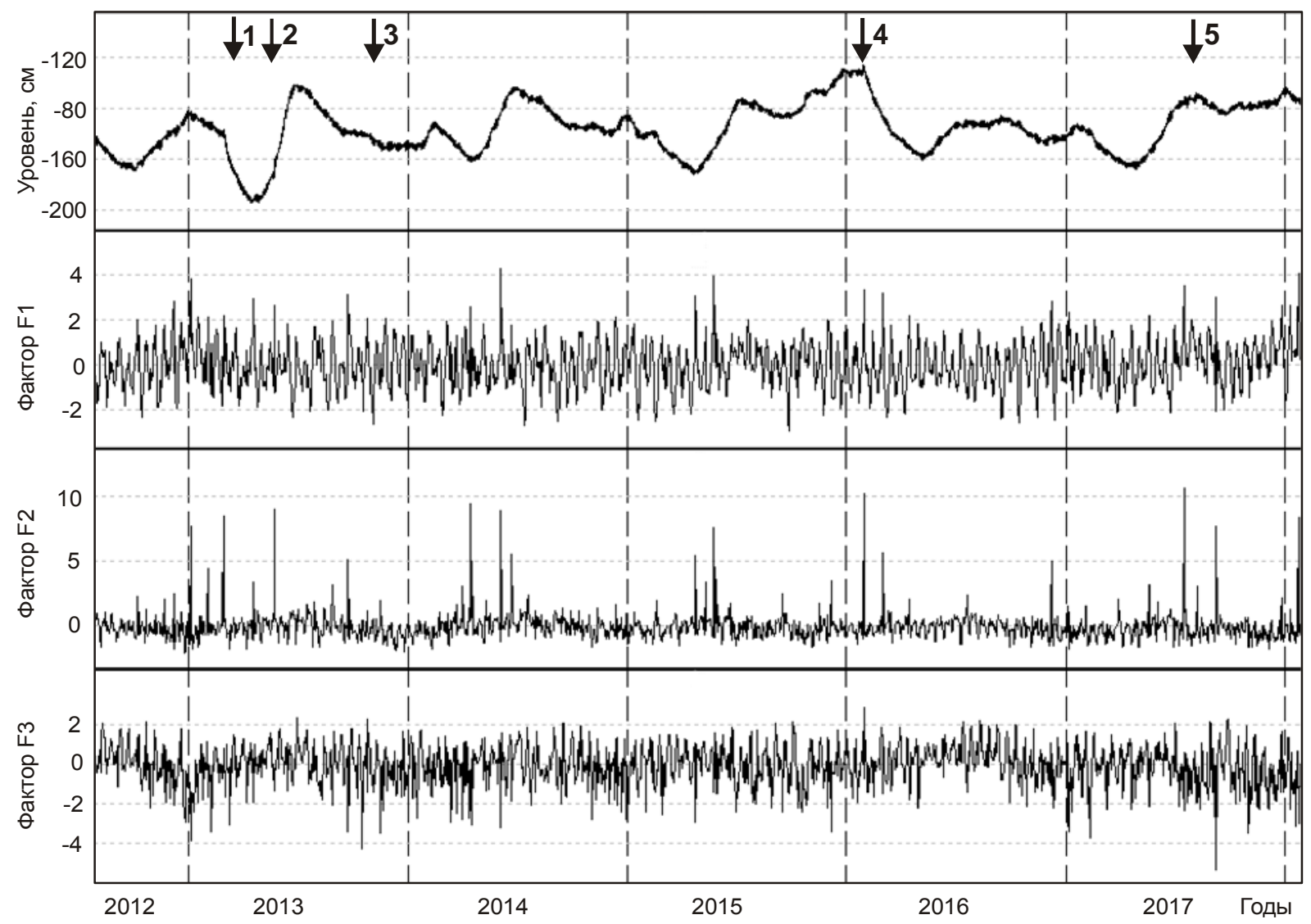

Рис. 5. Графики ортогональных общих факторов F1, F2, F3 набора восьми свойств временного ряда уровня воды после компенсации влияния атмосферного давления $U_{k}(t)$ (верхний график) в последовательных окнах длиной 1 сут. Стрелками показаны землетрясения (см. таблицу) 
8-мерных векторов свойств временного ряда уровня подземных вод после компенсации влияния атмосферного давления.

\section{Кластерный анализ ортогональных общих факторов}

После понижения размерности множества векторов статистических свойств ряда $U_{k}(t)$ путем перехода к рассмотрению трех ортогональных общих факторов выделим кластеры в пространстве общих факторов F1, F2, F3, применив метод $k$-средних (от же ISODATA) [Айвазян и дp., 1989; Duda, Hart, 1973]. В нашем случае объекты классификации представляют собой точки в 3-мерном евклидовом пространстве, причем каждая компонента этих векторов имеет нулевое среднее и единичное стандартное отклонение. Поэтому логично ввести между векторами обычное евклидово расстояние. Рассмотрим облако 3-мерных векторов $f$ общих ортогональных факторов. Внутри минимального параллелепипеда, содержащего классифицируемые точки $f$, случайным образом располагаются центры пробных кластеров, причем число $q \geq 2$ таких кластеров фиксировано. Обозначим символом Г начальное случайное положение пробных кластеров. Для заданного расположения центров кластеров производится пробное разбиение множества точек по принципу минимума расстояния до того или иного центра. Пусть $c_{k}$, $k=1, \ldots, q$ - вектора центров кластеров, $n_{k}$-число точек в $k$-м кластере, $\sum_{k=1}^{q} n_{k}=M-$ общее число точек в разбиваемом множестве.

В нашем случае $M=2015$, что соответствует числу последовательных временных интервалов длиной 1 сут. Пусть $B_{k}$ - множество векторов, принадлежащих $k$-му кластеру. Вычислим вектора центров тяжестей получившихся кластеров: $r_{k}=\sum_{f \in B_{k}} \xi / n_{k}$. Если для всех векторов $c_{k}=r_{k}$, то разбиение завершается. В противном случае вектора центров кластеров $c_{k}$ перемещаются в центры тяжести $r_{k}$, производится новое разбиение на кластеры, вычисляются новые центры тяжестей, проверяется условие завершения разбиения и т.д. Процедура быстро сходится. Однако то разбиение на кластеры, которое получилось по завершении итераций, зависит от случайных положений центров пробных кластеров Г в самом начале итераций. Качество финального разбиения оценивается критерием компактности кластеров:

$$
J(q \mid \Gamma)=\sum_{k=1}^{q} \sum_{f \in B_{k}}\left|f-c_{k}\right|^{2} .
$$

Для заданного числа кластеров $q$ будем искать такое случайное начальное расположение Г, для которого величина (17) минимальна. Это достигается методом МонтеКарло: случайные эксперименты по вбрасыванию центров пробных кластеров внутрь облака точек повторяются большое число раз (ниже, при анализе конкретных данных, мы использовали $10^{4}$ попыток), после чего выбирается то разбиение, для которого реализовался минимум по Г.

Далее решается задача определения оптимального числа кластеров, на которое следует разбить множество признаков. Пусть $J_{0}(q)=\min _{\Gamma} J(q \mid \Gamma)$. Если последовательно уменьшать число пробных кластеров $q$ от некоторого достаточно большого значения до минимального $q=2$, то величина $J_{0}(q)$ будет монотонно увеличиваться, однако при оптимальном значении кластеров (если такое существует) она будет претерпевать излом. Более эффективный метод выявления оптимального числа кластеров состоит в использовании псевдо-F-статистики [Vogel, Wong, 1979] и заимствован из дисперсионного анализа: 


$$
\operatorname{PFS}(q)=(M-q) \sum_{k=1}^{q} n_{k}\left|c_{k}-r_{0}\right|^{2} /\left((q-1) \cdot J_{0}(q)\right),
$$

где $r_{0}=\sum f / M$ - общий центр тяжести всего классифицируемого множества точек. Оптимальному значению числа кластеров соответствует точка максимума функции (18).

На рис. 6 представлена зависимость псевдо-F-статистики от числа пробных кластеров, из которой видно, что оптимальное число кластеров в пространстве ортогональных общих факторов F1, F2, F3 равно 4.

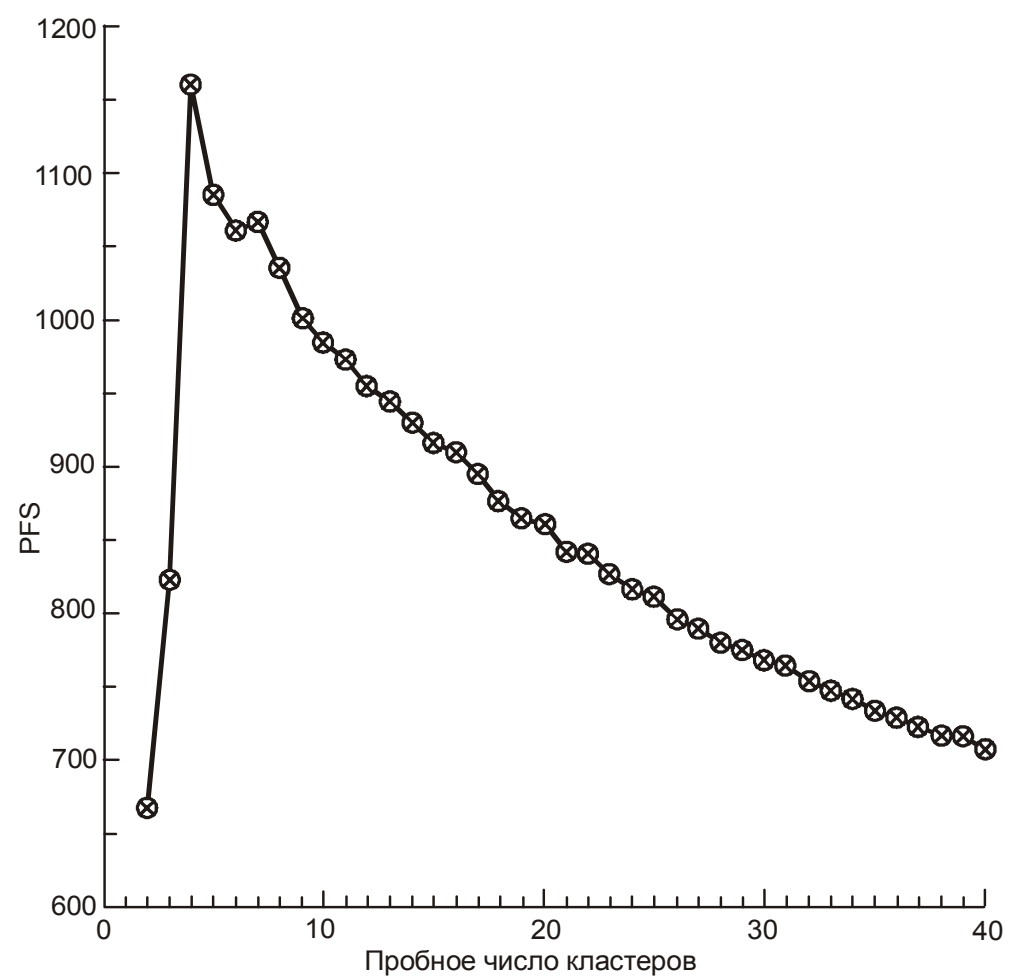

Рис. 6. График псевдо-F-статистики для кластеризации трех ортогональных общих факторов F1, F2, F3

На рис. 7 показана последовательность переходов между выделенными четырьмя состояниями временного ряда $U_{k}(t)$. Из 2015 значений (суток) состояние 1 , выделяемое по кластеру 1, проявлялось 27 раз, состояние $2-810$, состояние $3-722$ и состояние $4-$ 456 раз. Таким образом, вероятности нахождения временного ряда в каждом из выделенных состояний, представленных на рис. 7, равны $0.013,0.402,0.358,0.226$ соответственно для состояний 1-4. Таким образом, состояние 1 , выделяемое по кластеру 1 , можно считать “аномальным", а остальные три состояния, выделяемые по кластерам 2-4,фоновыми.

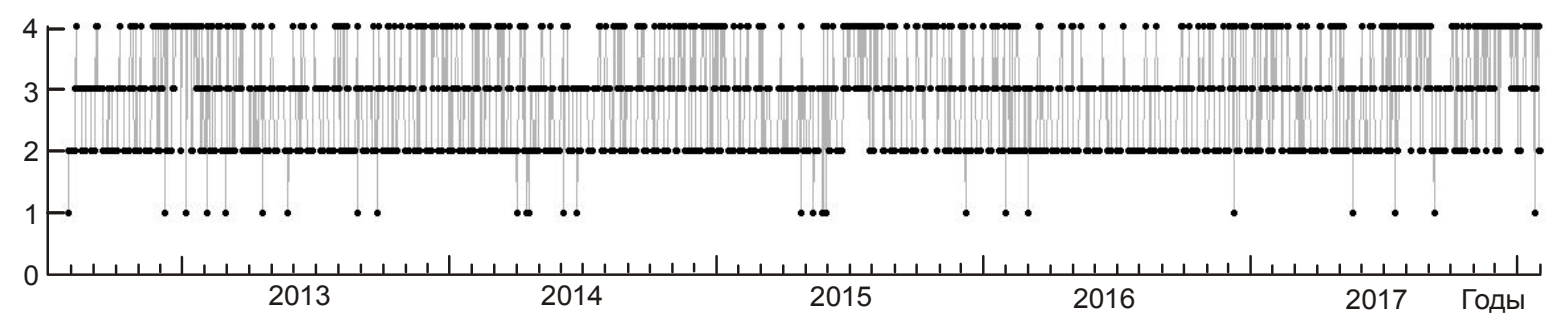

Рис. 7. Последовательность переходов между четырьмя кластерами статистических свойств временных фрагментов длиной 1 сут временного ряда приращений уровня воды $U_{k}(t)$, скважина Ю3-5 


\section{Геофизическая интерпретация результатов статистического анализа}

В результате применения изложенной методики обработки уровнемерных данных получены временные ряды статистических параметров, включающие набор из 8 свойств временного ряда (см. рис. 4), трех ортогональных общих факторов F1, F2 и F3 (см. рис. 5) и проявлений четырех кластеров статистических свойств фрагментов длиной 1 сут для временного ряда $U_{k}(t)$ (см. рис. 7). Дискретизация всех статистических параметров составляет 1 сут при длине временных рядов 2015 сут.

Дальнейший анализ полученных статистических параметров был направлен на оценку их чувствительности к различным естественным и техногенным воздействиям на гидрогеодинамический режим скважины. Основное внимание уделялось анализу связи между проявлениями “аномального" кластера 1 (см. рис. 7) и нарушенными состояниями наблюдаемого объекта. Даты нарушений гидрогеодинамического режима вследствие косейсмических вариаций уровня при сильных землетрясениях (см. таблицу) и пяти случаев проведения методических работ с внедрением в ствол скважины известны, общее число таких воздействий составляет 10 (рис. 8).

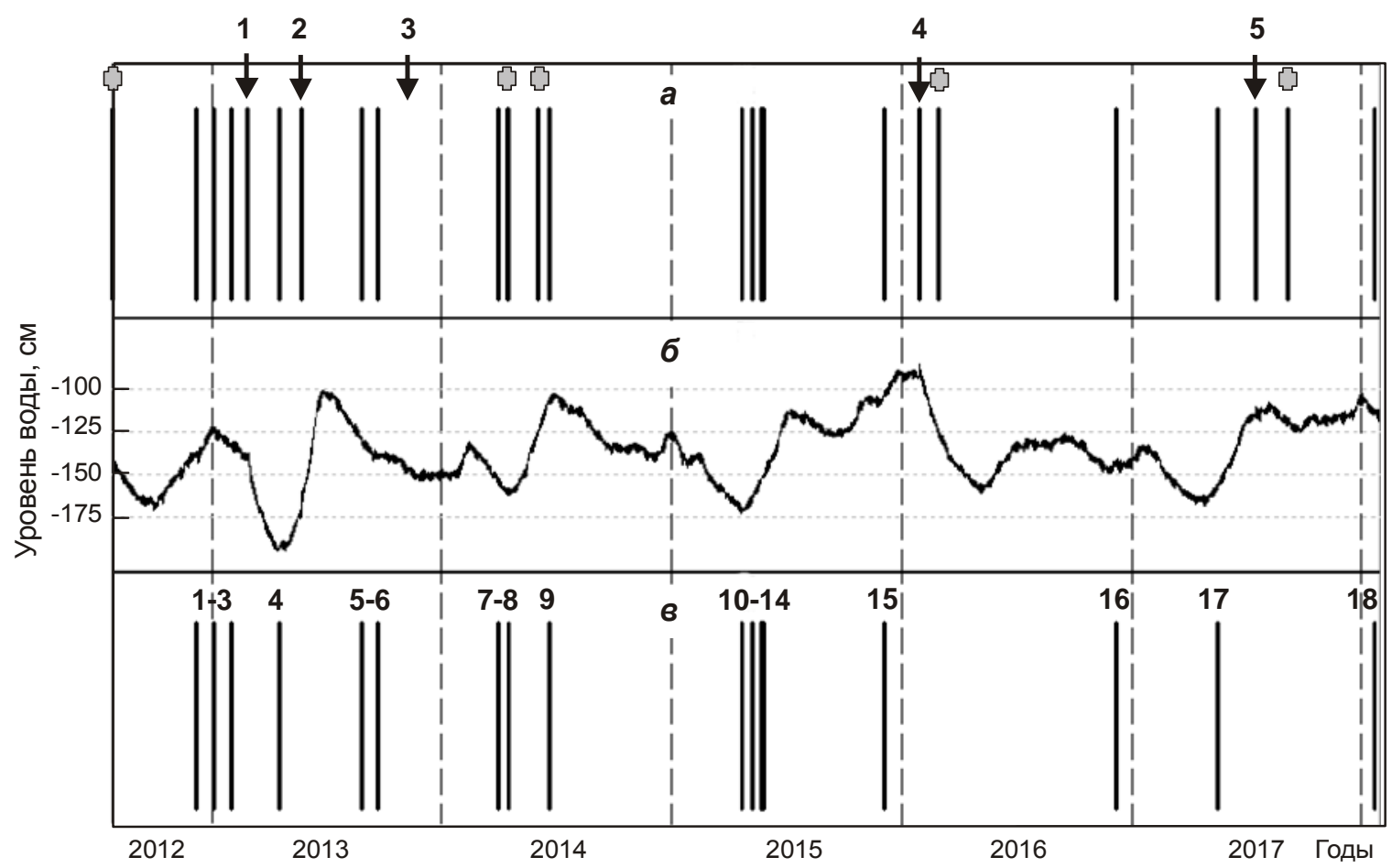

Рис. 8. Распределение во времени кластера $1(a)$ в сопоставлении с временным рядом $U_{k}(t)(б)$, сильными землетрясениями (показаны стрелками, цифры - номера землетрясений по таблице) и датами работ на скважине, сопровождающихся внедрением в ее ствол (показаны серыми крестами). Пояснения по графику (в) см. в тексте

Из пяти дат возникновения сильных землетрясений (см. таблицу) в четырех случаях (землетрясения 1-2, 4-5) проявлялся кластер 1 (рис. 8, a). Событие 12.11.2013 г. не сопровождалось проявлением кластера 1. Отметим, что для этого землетрясения с наименьшей магнитудой интенсивность сотрясений в районе скважины составляла всего 3-4 балла, ко- и постсейсмические эффекты в 5-минутных вариациях уровня воды не проявлялись.

Во всех пяти случаях проведения технических работ с внедрением в ствол скважины проявлялся кластер 1. Таким образом, из десяти известных случаев нарушения гидрогеодинамического режима скважины в девяти случаях (90\%) проявлялся 
“аномальный кластер 1, что является свидетельством достаточной чувствительности рассматриваемого способа обработки уровнемерных данных для диагностики кратковременных возмущений гидрогеодинамического режима скважины Ю3-5.

При ощутимых местных и при сильных удаленных землетрясениях продолжительности ко- и постсейсмических эффектов в изменениях уровня воды обычно составляют не более десятков минут-первых часов. После таких землетрясений восстановление гидрогеодинамического режима скважины происходит сравнительно быстро, что обусловлено достаточно высокой водопроводимостью водовмещающих пород $\left(7.8 \mathrm{~m}^{2} /\right.$ сут). По этой же причине релаксация возмущений уровня воды в результате технических работ также происходит в течение непродолжительного времени - не более 6-8 ч. Таким образом, интервал оценивания статистических свойств исследуемого временного ряда в 1 сут является достаточным для диагностики относительно кратковременных возмущений гидрогеодинамического режима скважины.

В случае трех наиболее сильных местных землетрясений, сопровождающихся сотрясениями 5 и более баллов по шкале $M S K-64$, постсейсмические вариации уровня воды развивались в течение месяцев, как, например, 1.5-месячное понижение уровня воды после землетрясения 28.02.2013 г. (см. рис. 2, б). Рассматриваемый метод обработки уровнемерных данных не позволяет выделять такие длительные гидрогеосейсмические вариации уровня воды. Их диагностика обеспечивается применением традиционного метода выделения низкочастотного тренда в изменениях уровня воды после компенсации баровариаций и подавления приливных суточных и полусуточных вариаций уровня воды [Копьлова, 2001, 2006а, 2009].

Если убрать из рассмотрения 9 случаев проявления кластера 1, связанных с возмущениями гидродинамического режима скважины при косейсмических эффектах и технических мероприятиях (33\%), то остается еще 18 случаев (67\%) его проявления (см. рис. 8, в). К возможным причинам появления кластера 1 мы относим кратковременные флуктуации гидродинамического напора, колебания уровня воды при прохождении сейсмических волн от сильных удаленных землетрясений (гидросейсмы), процессы подготовки сильных местных землетрясений, экстремальные метеорологические условия (циклоны, сильные порывы ветра, резкие изменения атмосферного давления), а также техногенные воздействия на режим скважины, расположенной в жилой зоне г. Елизово вблизи аэропорта и автотрассы.

Флуктуации гидростатического напора. Восемь случаев проявления кластера 1 (№№ 7-9 и 10-14 на нижнем графике на рис. 8) приходятся на интервалы времени с апреля по май в 2014 и 2015 гг. В эти годы сильные землетрясения на Камчатке не происходили, и наблюдался нормальный сезонный ход уровня воды. Это показывает, что “аномальный” кластер 1 может быть связан с процессами формирования напора подземных вод. Ранее особенности сезонного формирования напора в районе скважины Ю3-5 рассматривались в работе [Болдина, Копылова, 2017], в которой приводится годовой график изменения гидростатического напора по данным многолетних наблюдений. В соответствии с этим графиком в апреле-мае осуществляется переход от минимальной величины напора к его росту вследствие смены фазы преимущественного подземного стока (сезонное понижение уровня) фазой инфильтрационного питания и роста давления (повышение уровня воды). Наиболее вероятной причиной проявления кластера 1 в апреле-мае могут быть кратковременные вариации напора, связанные с инфильтрационным питанием подземных вод и локальными эффектами их перетекания между отдельными слоями водовмещающих пород с различными фильтрационными свойствами.

Гидросейсмы. Колебания уровня воды при прохождении сейсмических волн от сильных удаленных землетрясений также могут быть причиной проявления кластера 1. 
Например, проявление кластера 1 под номером 18 (см. рис. 8, в) совпадает по дате (23.01.2018 г.) с землетрясением на Аляске с $M_{w}=7.9$ (данные USGS), произошедшем на эпицентральном расстоянии $d_{e}=3400$ км. Это землетрясение сопровождалось колебаниями уровня воды в скважине Ю3-5 в течение 15 мин с максимальной амплитудой 7 см.

За время наблюдений на скважине Ю3-5 в мире по данным USGS происходили и другие сильные землетрясения: 01.04.2014 г. в Чили с $M_{w}=8.2$ на эпицентральном расстоянии $d_{e}=13300$ км; 25.04.2015 г. в Непале, $M_{w}=7.8, d_{e}=6100$ км; 16.09.2015 г. в Чили, $M_{w}=8.3, d_{e}=14600$ км; 08.09.2017 г. в Мексике, $M_{w}=8.1, d_{e}=7400$ км. Сейсмические волны от этих землетрясений сопровождались слабо выраженными колебаниями уровня воды в скважине Ю3-5 в течение времени от 1 до 6 ч с амплитудами 0.4-2 см. При этом в даты этих землетрясений кластер 1 не проявлялся.

Влияние прочессов подготовки землетрясений как возможной причины аномальных состояний режима скважины и проявления кластера 1 рассматривалось путем сопоставления времен возникновения сильных местных землетрясений (см. таблицу) и проявлений кластера 1 перед ними в течение времени до нескольких месяцев. При этом девять проявлений кластера 1 , связанных с косейсмическими и известными техногенными причинами, исключались из рассмотрения.

Мы полагали, что возможной причиной проявления “аномального” кластера 1 на интервале времени до нескольких месяцев перед землетрясениями (см. таблицу и стрелки на рис. $8, a$ ) могли быть кратковременные возмущения гидродинамического режима скважины при подготовке сейсмических событий. Такое предположение основано на пространственно-временных закономерностях проявления гидрогеологических (гидрогеодинамических и гидрогеохимических) предвестников перед сильными камчатскими землетрясениями, установленных по результатам наблюдений за параметрами подземных вод в глубоких скважинах на территории Петропавловского геодинамического полигона. В [Копылова, 2006а,б] показано, что предвестники в изменениях уровня и химического состава подземных вод проявляются перед землетрясениями с $M_{w}=6.6-7.8$ на эпицентральных расстояниях до первых сотен км в течение времени от первых недель до девяти месяцев. Перед Жупановским землетрясением гидрогеодинамический предвестник в скважине ЮЗ-5 проявлялся в течение 3.5 мес. [Болдина, Konblлова, 2017].

С учетом чувствительности кластера 1 к кратковременным возмущениям гидродинамического режима скважины и общих закономерностей связи гидрогеологических предвестников и сильных камчатских землетрясений можно полагать, что девять случаев проявления кластера 1 (№№ 1-3, 4, 5-6, 15 и 16-17) могли быть связаны с процессами подготовки землетрясений из таблицы. Заблаговременность проявления кластера 1 перед землетрясениями (см. таблицу) составляла от 25 до 220 сут при средней величине 72 сут или 2.4 мес. (см. рис. 8, в).

Краткий анализ возможных причин проявления кластера 1 показывает, что он может быть связан как с сейсмическими процессами, так и с другими природными и техногенными факторами, и это необходимо учитывать при использовании рассмотренного метода статистической обработки уровнемерных данных в задачах геофизического мониторинга и поиска предвестников землетрясений.

\section{Заключение}

Представленный метод статистической обработки уровнемерных данных с выделением “аномального” кластера трех ортогональных факторов в изменениях совокупности из восьми статистических параметров на суточных интервалах 5-минутного ряда вариаций уровня воды после компенсации в нем влияния атмосферного давления 
позволяет диагностировать кратковременные нарушения гидрогеодинамического режима наблюдательной скважины. Тем самым, он существенно дополняет традиционный метод обработки уровнемерных данных, ориентированный на выделение низкочастотного тренда в изменениях уровня воды и соответствующих низкочастотных сигналов в изменении давления подземных вод.

Проверка чувствительности метода по выделению кратковременных возмущений гидрогеодинамического режима скважины с использованием известных косейсмических и техногенных воздействий показывает его достаточную надежность. Большая часть таких известных возмущений (9 из 10) была диагностирована по появлению “аномального" кластера, т.е. эти возмущения были выделены с использованием рассмотренного метода обработки экспериментальных данных. Это показывает, что предложенный метод может найти применение в системе геофизического мониторинга в Камчатском регионе для выделения кратковременных возмущений гидрогеодинамического режима скважины Ю3-5 и других наблюдательных скважин, включая возможные эффекты в изменениях уровня воды на стадиях подготовки сильных землетрясений. При этом важным условием применения метода является обеспечение непрерывности наблюдений и высокого качества исходных данных, а также применение процедуры компенсации баровариаций в изменениях уровня воды.

Было обнаружено, что довольно большая часть проявлений “аномального” кластера $(67 \%)$ не имеет очевидной связи с сейсмическими или техногенными процессами, и это необходимо учитывать при использовании рассмотренного метода в задачах геофизического мониторинга и поиска предвестников землетрясений. Вместе с тем, несомненным достоинством предложенного метода является возможность выделения скрытых в шуме кратковременных аномальных состояний наблюдательных скважин при оперативной обработке больших массивов уровнемерных данных, что не обеспечивается при использовании традиционных методов.

Остается также открытым вопрос об оптимальном наборе статистических параметров, характеризующих свойства временного ряда $U_{k}(t)$ внутри последовательных временных фрагментов длиной 1 сут, т.е. о размерности и составе вектора параметров $\zeta$ в (9). Для проверки работоспособности метода по выделению кратковременных нарушений режима скважины проводились эксперименты с различными наборами статистик от 8 (представлен в настоящей работе) до 12 с добавлением в вектор $\zeta$ от одного до четырех временных рядов дополнительных параметров, при этом другие условия счета не изменялись. Во всех вариантах расчетов были получены одинаковые результаты, заключающиеся в выделении трех общих ортогональных факторов, описывающих используемые наборы статистик, и затем в получении четырех кластеров в пространстве ортогональных общих факторов, один из которых проявлялся с низкой вероятностью и мог рассматриваться в качестве “аномального".

\section{Финансирование}

Работа выполнена при поддержке Российского фонда фундаментальных исследований, гранты №№ 18-05-00133, 18-05-00337.

\section{Конфликт интересов}

Авторы заявляют об отсутствии конфликта интересов. 


\section{Литература}

Айвазян С.А., Бухштабер В.М., Енюков И.С., Мешалкин Л.Д. Прикладная статистика. Классификация и снижение размерности. М.: Финансы и статистика, 1989. $607 \mathrm{c.}$

Болдина С.В., Копылова Г.Н. Косейсмические эффекты сильных камчатских землетрясений 2013 г. в изменениях уровня воды в скважине Ю3-5 // Вестник КРАУНЦ. Науки о Земле. 2016. № 2. Вып. 30. С.66-76.

Болдина С.В., Копылова Г.Н. Эффекты Жупановского землетрясения 30 января 2016 г., Mw=7.2, в изменениях уровня воды в скважинах Ю3-5 и Е-1, Камчатка // Геодинамика и тектонофизика. 2017. T. 8, № 4. C.863-880. https://doi.org/10.5800/GT-2017-8-4-0321

Виноградов Е.А., Горбунова Э.М., Кабыченко Н.В. и др. Мониторинг уровня подземных вод по данным прецизионных измерений // Геоэкология. Инженерная геология. Гидрогеология. Геокриология. 2011. № 5. С.439-449.

Киссин И.Г. Гидрогеологический мониторинг земной коры // Физика Земли. 1993. № 8. С.58-69.

Киссин И.Г. Флюиды в земной коре: геофизические и тектонические аспекты. М.: Наука, 2009. $328 \mathrm{c}$.

Копылова Г.Н. Изменения уровня воды в скважине Елизовская-1, Камчатка, вызванные сильными землетрясениями (по данным наблюдений в 1987-1998 гг.) // Вулканология и сейсмология. 2001. № 2. С.39-52.

Копылова Г.Н. Изменения уровня воды в скважине Ю3-5, Камчатка, вызванные землетрясениями // Вулканология и сейсмология. 2006а. № 6. С.52-64.

Копылова Г.Н. Сейсмичность как фактор формирования режима подземных вод // Вестник КРАУНЦ. Науки о Земле. 2006б. № 1. Вып. 7. С.50-66.

Копылова Г.Н. Оценка информативности уровнемерных наблюдений в скважинах для поиска гидрогеодинамических предвестников землетрясений (на примере Камчатки) // Геофизические исследования. 2009. Т. 10, № 2. С.56-68.

Копылова Г.Н., Болдина С.В. Оценка пороупругих параметров резервуара подземных вод (по данным уровнемерных наблюдений на скважине Ю3-5, Камчатка) // Вулканология и сейсмология. 2006. № 2. С.17-28.

Копылова Г.Н., Болдина С.В. О механизме гидрогеодинамического предвестника Кроноцкого землетрясения 5 декабря 1997 Г., $M_{w}=7.8$ // Тихоокеанская геология. 2012. Т. 31, № 5. C.104-114.

Копьлова Г.Н., Болдина С.В., Смирнов А.А., Чубарова Е.Г. Опыт регистрации вариаций уровня и физико-химических параметров подземных вод в пьезометрических скважинах, вызванных сильными землетрясениями (на примере Камчатки) // Сейсмические приборы. 2016. T. 52, № 4. C.43-56. https://doi.org/10.21455/si2016.4-4

Копылова Г.Н., Любушин А.А., Малугин В.А., Смирнов А.А., Таранова Л.Н. Гидродинамические наблюдения на Петропавловском полигоне, Камчатка // Вулканология и сейсмология. 2000. № 4. C.69-79.

Копылова Г.Н., Стеблов Г.М., Болдина С.В., Сдельникова И.А. О возможности оценок косейсмической деформации по данным уровнемерных наблюдений в скважине // Физика Земли. 2010. № 1. C.51-61. https://doi.org/10.1134/S1069351310010040

Любушин А.А. Анализ данных систем геофизического и экологического мониторинга. М.: Наука, 2007. $228 \mathrm{c}$.

Любушин А.А. Тренды и ритмы синхронизации мультифрактальных параметров поля низкочастотных микросейсм // Физика Земли. 2009. № 5. С. 15-28.

Любушин А.А. Статистики временных фрагментов низкочастотных микросейсм: их тренды и синхронизация // Физика Земли. 2010. № 6. С.86-96.

Любушин А.А. Прогностические свойства случайных флуктуаций геофизических характеристик // Биосфера. 2014. № 4. С.319-338.

Любушин А.А., Лежнев М.Ю. Анализ изменчивости функции отклика уровня подземных вод на баровариации на Южных Курилах (о. Шикотан) // Физика Земли. 1995. № 8. С.79-84. 
Любушин А.А., Малугин В.A. Статистический анализ отклика уровня подземных вод на вариации атмосферного давления // Физика Земли. 1993. № 12. С.74-80.

Любушин А.А., Малугин В.А., Казанщева О.С. Мониторинг приливных вариаций уровня подземных вод в группе водоносных горизонтов // Физика Земли. 1997. № 4. С.52-64.

Любушин А.А., Малугин В.А., Казанщева О.С. Выделение “медленных событий" в асейсмическом регионе // Физика Земли. 1999. № 3. С.35-44.

Любушин А.А., Фарков Ю.А. Синхронные компоненты финансовых временных рядов // Компьютерные исследования и моделирование. 2017. Т. 9, № 4. С.639-655. https://doi.org/ 10.20537/2076-7633-2017-9-4-639-655

Медведев С.В., Шпонхойер В., Карник В. Шкала сейсмической интенсивности MSK-64. М.: МГК АН СССР, $1965.11 \mathrm{c}$.

Мельхиор П. Земные приливы. М.: Мир, 1968. 482 с.

Малла С. Вейвлеты в обработке сигналов. М.: Мир, 2005. 671 с.

Сильные камчатские землетрясения 2013 года / Под ред. В.Н. Чеброва. ПетропавловскКамчатский: Холд. комп. "Новая книга", 2014. 252 с.

Чебров В.Н., Кугаенко Ю.А., Абубакиров И.Р., Дрознина С.Я., Иванова Е.И., Матвеенко Е.А., Митюшкина С.В., Ототюк Д.А., Павлов В.М., Раевская А.А., Салтыков В.А., Сенюков С.Л., Серафимова Ю.К., Скоркина А.А., Титков Н.Н., Чебров Д.В. Жупановское землетрясение 30.01.2016 г. с $K_{\mathrm{s}}=15.7, M w=7.2, I=6$ (Камчатка) // Вестник КРАУНЦ. Науки о Земле. 2016. № 1. Вып. 29. С. 5-16.

Чебров В.Н., Салтыков В.А., Серафимова Ю.К. Прогнозирование землетрясений на Камчатке. По материалам работы Камчатского филиала Российского экспертного совета по прогнозу землетрясений, оценке сейсмической опасности и риска в 1998-2009 гг. М.: Светоч Плюс, $2011.304 \mathrm{c}$.

Чебров Д.В., Кугаенко Ю.А., Абубакиров И.Р., Ландер А.В., Павлов В.М., Салтыков В.А., Титков Н.Н. Ближне-Алеутское землетрясение 17.07.2017 г. с $M_{w}=7.8$ на границе Командорской сейсмической бреши // Вестник КРАУНЦ. Науки о Земле. 2017. № 3. Вып. 35. С.2225.

Фирстов П.П., Копылова Г.Н., Соломатин А.В., Серафимова Ю.К. О прогнозировании сильного землетрясения в районе полуострова Камчатка // Вестник КРАУНЦ. Науки о Земле. 2016. № 4. Вып. 32. С.106-114.

Anderson T.W., Rubin H. Statistical inference in factor analysis. Proc. $3^{\text {rd }}$ Berkley Symp. on Math. Statistics and Probability, 1956. V.5. P.111-150.

Box G.E.P., Jenkins G.M. Time series analysis. Forecasting and control. Holden-Day. San Francisco, Cambridge, London, Amsterdam, 1970. 537 p.

Bredehoeft J.D. Response of well-aquifer systems to earth tides // J. Geophys. Res. 1967. V. 72, N 12. P.3075-3087.

Cramer H. Mathematical Methods of Statistics. Princeton University Press, 1999. 575 p.

Donoho D.L., Johnstone I.M. Adapting to Unknown Smoothness via Wavelet Shrinkage // Journal of the American Statistical Association. 1995. V. 90, N 432. P.1200-1224.

Duda R.O., Hart P.E. Pattern classification and scene analysis. John Wiley \& Sons, N.Y., London, Sydney, Toronto, 1973. $527 \mathrm{p}$.

Harman H.H. Modern factor analysis. Chicago: University of Chicago Press, 1967. 474 p.

Huber P.J., Ronchetti E.M. Robust Statistics, Second Edition. John Wiley \& Sons, Inc, 2009. 354 p. https://doi.org/10.1002/9780470434697.ch1

Igarashi G., Wakita H. Tidal responses and earthquake-related changes in the water level of deep wells // J. Geophys. Res. 1991. V. 96, N B3. P.4269-4278.

Kashyap R.L., Rao A.R. Dynamic stochastic models from empirical data. New York, San Francisco, London: Acad. Press, 1976. 377 p.

Lawle D.N., Maxwell A.E. Factor analysis as a statistical method. New York: American Elsevier, 1971. $117 \mathrm{p}$.

Lyubushin A. Prognostic properties of low-frequency seismic noise // Natural Science. 2012. V. 4, N 8A. P.659-666. DOI: 10.4236/ns.2012.428087 
Osorio I., Lyubushin A., Sornette D. Automated seizure detection: Unrecognized challenges, unexpected insights // Epilepsy \& Behavior. 2011. V. 22, N 1. P.S7-S17. DOI: 10.1016/ j.yebeh.2011.09.011

Roeloffs E.A. Hydrologic precursors to earthquakes: A review // Pure Appl. Geophys. 1988. V. 126. P.177-209.

Roeloffs E.A., Burford S.S., Riley F.S., Records A.W. Hydrologic effects on water level changes associated with episodic fault creep near Parkfield, California // J. Geophys. Res. 1989. V. 94. P.12387-12402.

Rojstaczer S., Agnew D.S. The influence of formation material properties on the response of water levels in wells to Earth tides and atmospheric loading. // J. Geophys. Res. 1989. V. 94. P.1240312411.

Vogel M.A., Wong A.K.C. PFS Clustering method // IEEE Transactions on Pattern Analysis and Machine Intelligence. 1979. V. 1. P.237-245. https://doi.org/10.1109/TPAMI.1979.4766919

Wang C.-Y., Manga M. Earthquakes and Water. Lecture Notes in Earth Sciences 114. Springer, Berlin, 2010. 249 p. https://doi.org/10.1007/978-3-642-00810-8

Сведения об авторах

КОПЫЛОВА Галина Николаевна - доктор геолого-минералогических наук, доцент, главный научный сотрудник, заведующая лабораторией, Камчатский филиал Федерального исследовательского центра "Единая геофизическая служба РАН". 683006, Россия, г. ПетропавловскКамчатский, бульвар Пийпа, д. 9. Тел.: +7(4152)-43-18-49. E-mail: gala@emsd.ru

ЛЮБУШИН Алексей Александрович - доктор физико-математических наук, профессор, главный научный сотрудник, заведующий лабораторией, Институт физики Земли им. О.Ю. Шмидта РАН. 123242, Россия, г. Москва, ул. Большая Грузинская, д. 10, стр. 1. Тел.: +7(499) 254-23-50. E-mail: lubushin@ifz.ru

БОЛДИНА Светлана Васильевна - кандидат геолого-минералогических наук, старший научный сотрудник, Камчатский филиал Федерального исследовательского центра "Единая геофизическая служба РАН”. 683006, Россия, г. Петропавловск-Камчатский, бульвар Пийпа, д. 9. Тел.: +7(4152) 43-18-35. E-mail: boldina@emsd.ru

\title{
METADATA IN ENGLISH
}

\author{
About the journal \\ SEISMICHESKIE PRIBORY, ISSN: 0131-6230, eISSN: 2312-6965, DOI: 10.21455/si, \\ http://elibrary.ru/title_about.asp?id=25597 \\ English Translation: Seismic Instruments, ISSN: 0747-9239 (Print) 1934-7871 (Online), \\ https://link.springer.com/journal/11990
}

\section{Statistical analysis of precision water level data observations in a seismically active region (on example of the YuZ-5 well, Kamchatka)}

\author{
G.N. Kopylova ${ }^{1}$, A.A. Lyubushin ${ }^{2}$, S.V. Boldina ${ }^{1}$ \\ ${ }^{1}$ Kamchatka branch of Geophysical Survey of the Russian Academy of Sciences, \\ Petropavlovsk-Kamchatsky, Russia \\ ${ }^{2}$ Schmidt Institute of Physics of the Earth, Russian Academy of Sciences, Moscow, Russia \\ Corresponding author: G.N. Kopylova, e-mail: gala@emsd.ru
}




\begin{abstract}
The results of statistical analysis of the long-term time series of the water level observations in the YuZ-5 well located on the territory of the Petropavlovsk geodynamic site, Kamchatka, are presented. The used data from 27.07.2012 to 01.02.2018 are noteworthy for their detail (the interval of the level and atmospheric pressure registration was 5 minutes, the sensitivity of the water level recording $\pm 0.1 \mathrm{~cm}$, atmospheric pressure $\pm 0.1 \mathrm{hPa}$ ), and the fact that five strong earthquakes with $\mathrm{Mw}=6.5-8.3$ occurred on epicentral distances $d_{e}=80$ $700 \mathrm{~km}$ during the observations. A good study of the hydrodynamic regime of the observation well over a long period and the high quality of the data observations in conjunction with data on strong seismic events allow us to consider the possibility of using the formalized statistical methods of water level data processing for diagnostics of abnormal conditions of the observed object. As a result of the application of factor and cluster analysis to the sequence of multidimensional vectors of statistical properties of a time series of the water level data in successive time windows in one day after adaptive compensation of atmospheric pressure, four different statistically significant states of the time series were distinguished, between which switching occurs in the time. Geophysical interpretation of the allocated "anomalous" condition of the water level time series is carried out in comparison with the strong earthquakes, the technical actions in the observation well and seasonal features of the hydrodynamic regime of the observation well. It is shown that the presented method of water level data processing can find application in the field of geophysical monitoring and prediction of earthquakes.
\end{abstract}

Keywords: well, water level, earthquake, precursor, Kamchatka, time series, adaptive filtration, factor analysis, cluster analysis

\title{
About the authors
}

KOPYLOVA Galina Nikolaevna - Doctor of Geological and Mineralogical Sciences, docent, Chief scientist, Head of the laboratory, Kamchatka Branch of Geophysical Survey RAS (KB GS RAS). 683006, Russia, Petropavlovsk-Kamchatsky, 9 Piip Boulevard. Tel: 8(4152)431849. e-mail: gala@emsd.ru

LYUBUSHIN Alexey Alexandrovich - Doctor of Physical and Mathematical Sciences, professor, Chief scientist, Head of the laboratory, Schmidt Institute of Physics of the Earth of the Russian Academy of Sciences. 123242, Russia, Moscow, Bolshaya Gruzinskaya str., 10-1. Tel: 8(499)254-23-50. email: lyubushin@yandex.ru

BOLDINA Svetlana Vasil'evna - Candidate of Geological and Mineralogical Sciences, Senior scientist, Kamchatka Branch of Geophysical Survey RAS (KB GS RAS). 683006, Russia, PetropavlovskKamchatsky, 9 Piip Boulevard. Tel: 8(4152)431835. e-mail: boldina@emsd.ru

Cite this article as: Kopylova G.N., Lyubushin A.A., Boldina S.V. Statistical analysis of precision water level data observations in a seismically active region (on example of the YuZ-5 well, Kamchatka). Seismicheskie Pribory, 2019, Vol. 55, no. 1, pp. 5-28. [in Russian]. https://doi.org/ 10.21455/si2019.1-1

English translation of the article will be published in Seismic Instruments, ISSN: 0747-9239 (Print) 1934-7871 (Online), https://link.springer.com/journal/11990), 2020, Volume 56, Issue 1. 